\title{
POLYHYDROYALKANOATES: FROM BASIC RESEARCH AND MOLECULAR BIOLOGY TO APPLICATION
}

\author{
Amro Abd Al Fattah Amara \\ Genetic Engineering and Biotechnology Research Institute, \\ Mubarak City for Scientific Research and Technological Applications. Egypt. \\ e-mail:amroamara@web.de
}

\begin{abstract}
This review describes the Polyhydroxyalkanoate (PHA), an intracellular biodegradable microbial polymer. PHAs is formed from different types of three hydroxyalkanoic acids monomers, each unit forms an ester bond with the hydroxyl group of the other one and the hydroxyl substituted carbon has $R$ configuration. The C-3 atom in $\beta$ position is branched with at least one carbon atom in the form of methyl group (C1) to thirteen carbons in the form of tridecyl (C13). This alkyl side chain is not necessarily saturated. PHAs are biosynthesized through regulated pathways by specific enzymes. PHAs are accumulated in bacterial cells from soluble to insoluble form as storage materials inside the inclusion bodies during unbalanced nutrition or to save organisms from reducing equivalents. PHAs are converted again to soluble components by PHAs depolymerases and the degraded materials enter various metabolic pathways. Until now, four classes of enzymes responsible for PHAs polymerization are known. PHAs were well studied regarding their promising applications, physical, chemical and biological properties. PHAs are biodegradable, biocompatible, have good material properties, renewable and can be used in many applications. The most limiting factor in PHAs commercialization is their high cost compared to the petroleum plastics. This review highlights the new knowledge and that established by the pioneers in this field as well as the factors, which affect PHAs commercialization.
\end{abstract}

KEYWORDS PhaC synthase, Polyhydroxyalkanoate, Polyhydroxybutyrate, Plastic, Application, commercialization

\section{INTRODUCTION}

\subsection{Polymers}

Polymers are naturally occurring or synthetic compounds, consisting of large molecules, made up of linked series of repeated monomers joined by chemical bonds through chemical reactions (polymerization, polycondensation, polyaddition) to form the polymer. Plastic is a generic name of synthetic, semi-synthetic or natural materials that can be moulded or extruded into objects, films, filaments or used to make, for example coatings and adhesives. It is mainly derived from petroleum oil. 


\subsection{Plastic Problems}

The manufacturing of plastic has increased significantly since the 1940 s and has successfully replaced wood, mud, metals, glass and other materials $[1,2,3,4]$. The low cost, stability, durability, good mechanical and thermal properties of plastic make it the best choice for widespread applications [5]. The extensive use of materials made from plastics causes a worldwide problem because they are non-degradable $[3,5,6,7]$.

Plastic packages take up about $1 / 3$ of the volume of municipal wastes because of their low density $[8,9,10]$. Plastics consistently make up 60 to $80 \%$ of the marine debris [11]. Barnes (2002) accounts the amount of debris around the coastline of the UK has doubled between 1994 and 1998, in parts of the Southern Ocean it increased 100-fold [12]. General data show that world production of packages is on the level of about 1500 million tons/year [10]. Three hundred and sixty thousand tons of plastic for the production of bottles have been manufactured in Europe in 2002 and the world currently needs around 140 million tons of plastic yearly [13]. Processing these plastics needed nearly 150 million tons of fossil fuels, which with their high treatment cost and the emission of toxic compounds like dioxin during plastic incineration increase the gravity of the problem [14].

\subsection{Biopolymers}

Steinbüshel has classified the biopolymers based on their chemical structure into eight classes: i) nucleic acids, ii) "polyamides" such as a protein poly-(amino acids), iii) polysaccharides, iv) organic polyoxoesters such as poly(hydroxyalkanoic acids), poly(malic acid) and cutin, v) polythioesters, iv) inorganic polyesters with polyphosphate, vii) polyisoprenoides such as natural rubber or Gutta-Percha and viii) polyphenols such as lignin or humic acids [15]. Not all biopolymers have the same properties, few species can be used as plastics and not all of them are biodegradable like polythioesters [16 - 18].

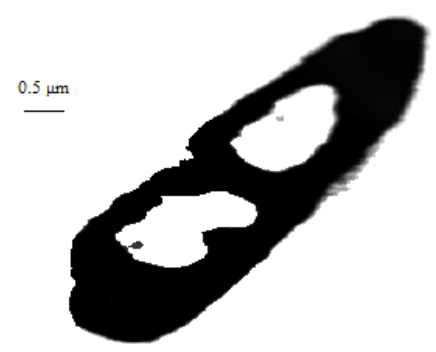

Fig. 1: Bacterial cells producing a PHA polymer (white granules inside the cell)

The most widely known bioplastics, which are produced by microbes, are polyhydroxyalkanoates (PHAs) and their derivatives [19-21]. PHAs can solve the solid waste problem by substituting petroleum plastic $[4,22]$. PHAs have proved to be similar in material properties to petroleum plastics, while PHAs are produced from renewable resources and are biodegradable [22, 23]. 


\subsection{History of PHAs}

PHAs are widely distributed within different microbial species and are accumulated intracellularly in the form of storage granules. Perhaps, the first report about lucent granules of PHAs in bacterial cells (Fig. 1) was made by Beijerinck in 1888 (reported in Chowdhury, 1963) [24]. The French scientist Maurice Lemoigne, who worked at the Lille branch of the Pasteur Institute - France, had the interest to characterize these inclusion bodies, which were found in Bacillus spp.

The work done by Lemoigne and co-workers were published in 27 publications from 1923 until 1951 [25]. Lemoigne was the first to report that the bacterial granules components (Lemoigne describes it also as reserved material) were not ether soluble, as in lipids, and later reported that polyhydroxybutanoate (PHB) is the major constituent of these granules. Using microscopic observations, saponification numbers, and autolysis whose solubility and melting point $\left(T_{m}\right)$ variation were correlated with molecular size proposed a polyester structure with formula $\left(\mathrm{C}_{4} \mathrm{H}_{6} \mathrm{O}_{2}\right)_{\mathrm{n}}$. Lemoigne has also reported that PHB could cast into film like cellulose nitrate material [25 - 29].

During the following years, interest in this unknown material was negligible. In 1953 Weibull had isolated the granules of Bacillus megaterium by dissolution of the cell wall with a lysozyme [30]. The first report on functions of PHB appeared in 1958 by Wilkinson and Wilkinson who obtained morphologically intact granules from Bacillus cereus using alkaline hypochlorite, and Macrae and Wilkinson in 1958 who described poly- $\beta$ hyroxybutyrate metabolism in washed suspensions of Bacillus cereus and Bacillus megaterium [31, 32]. Doudoroff and Stanier (1959) and Stainer et al., (1959) found that PHB can be produced by photosynthetic assimilation of organic compounds by phototrophic bacteria and they described that the reaction involved in the metabolic pathway is responsible for the biosynthesis of PHB from acetic acid [33, 34]. Merrick and Doudoroff (1961) isolated and described native PHB granules of hemoheterotropic bacteria, Rhodospirillum rubrum and B. megaterium [35]. In 1966, Lusty and Doudoroff have shown a study on depolymerases which were able to hydrolyse PHB [36]. Lundgren et al., (1965) showed that only the cells that are extracted with chloroform could yield high molecular weight PHB [37]. Schlegal at the University of Göttingen, Germany in 1961 observed that Cupriavidus necator (formally Wautersia eutropha, Ralstonia eutropha and Alcaligenes eutrophus), could accumulate very large amount of PHB in a media with low nitrogen content [38]. Merrick and Doudoroff (1964) were the first to identify the enzyme responsible for PHB polymerization which is the synthase or the polymerase as was known at that time followed by work done by Griebel et al., (1968) [39, 40]. Schlegal working with C. necator and Dawes working with Azotobacter berjerinckii (University of Hull, England) in 1973 simultaneously were the first to isolate and characterize the enzymes, which catalyse the PHB monomer synthesis [41, 42].

Wallen gave the first indication that the polymer discovered by Lemoigne may contain proportions of 3-hydroxyacids other than 3-hydroxybutyrate and Rohwedder, who, in 1974, reported heteropolymers of 3-hydroxybutyrate and 3-hydroxyvalerate in chloroform extracts of activated sewage sludge as major constituents with C6 and possibly C7 3hydroxyacids as minor components [43]. This heteropolymer had a lower melting point than PHB and, unlike the homopolymer, was soluble in hot ethanol. Findlay and White in 
1983, using GC analysis, detected at least 11 short-chain 3-hydroxyacids, the principal ones being $3 \mathrm{HB}$ and $3 \mathrm{HV}$ [44].

De Smet et al. characterized $\mathrm{PHA}_{\mathrm{MCL}}$ in Pseudomonas oleovorans during growth on octane [45]. Huisman et al. confirmed that $\mathrm{PHA}_{\mathrm{MCL}}$ accumulation was the common feature of fluorescent pseudomonads [46]. PHAs are also produced by gram-positive, gramnegative bacteria and phototrophic bacteria as well as archaea [47 - 52].

PhaC synthase from an extreme halophilic archaeon has been enzymologically and biochemically characterized [53, 54]. The first halobacterial PHAs synthase gene sequenced is from Haloarcula marismortui [55]. Another putative polyester synthase gene was identified in the genome of an uncultivated archaebacterium belonging to Crenarchaeota [56].

\section{PHAS NOMENCLATURE}

There are many ways to abbreviate PHAs species but two of them are the most dominant; they are based on the number of their carbon atom or classifying them to Short, Medium or Long Chain Length. PHAs created from three to five carbon atoms are called Short-Chain-Length, termed SCL, while PHAs with six to fourteen carbon atoms are called Medium-Chain-Length, and termed MCL [48]. In fact, even this abbreviation system is based on the number of $\mathrm{C}$ atoms in their monomeric unit's composition but at the same time it reflects the different physical properties where SCL PHAs are solid or semisolid while MCL PHAs are latex like, rubber or elastomers. The PHAs which contain more than fourteen carbon atom are called Long-Chain-Length (LCL). Genes coding for proteins involved in the biosynthesis of PHA are referred in alphabetical order as phaA ( $\beta$ ketothiolase), phaB (acetoacetyl-Co A reductase), phaC (PHA synthase), phaG (3hydroxyacyl-acyl carrier protein-Co A transacylase), etc. [48, 57].

The names of genes involved in PHAs degradation are referred to opposite alphabetical order such as phaZ for PHA depolymereses, phaY, phaX, phaW etc. The genes for phasins and regulator proteins are referred to as phaP and phaR, respectively. The origin of the gene or protein can be also referred to the first letter of the gene and the species as subscript e.g., phaC $\mathrm{Pa}$ refers to Pseudomonas aeruginosa. It is important to sign that using the numbering style to differentiate between the monomer structures is preferable when copolymer is present such as $\mathrm{P}(3 \mathrm{HB}-\mathrm{co}-4 \mathrm{HB})$. If the polymer is well known it is preferable to use their abbreviation instead of using SCL/MCL style. For example, polyhydroxybutyrate usually abbreviate as $\mathrm{PHB}$ or $\mathrm{P} 3(\mathrm{HB})$ and polyhydroxybutyrate-co-polyhydroxyvalirate abbreviate as $\mathrm{PHB}-\mathrm{co}-\mathrm{PHV}$ or $\mathrm{P}(3 \mathrm{HB}-\mathrm{co}$ $3 \mathrm{HV}$ ). Alternatively, in case of MCL PHAs and because of the big number of their monomeric composition $\mathrm{PHA}_{\mathrm{MCL}}$ is usually used. Finally, PHAs could be abbreviated using any of the described styles based on the situation. An example for the different abbreviation styles for polyhydroxybutyrate-co-polyhydroxyvalerate are PHB-co-PHV, $\mathrm{P} 3(\mathrm{HB}-c o-\mathrm{HV}), \mathrm{P}(3 \mathrm{HB}-c o-3 \mathrm{HV}), \mathrm{P}(3-\beta \mathrm{HB}-c o-3-\beta \mathrm{HV}), \mathrm{P} 3 \beta(\mathrm{HB}-c o-\mathrm{HV})$. Few authors are still using $\beta$ in PHA abbreviation. PHAs will refer to different kinds of polyhydroxyalkanoates including SCL, MSL and LCL. 


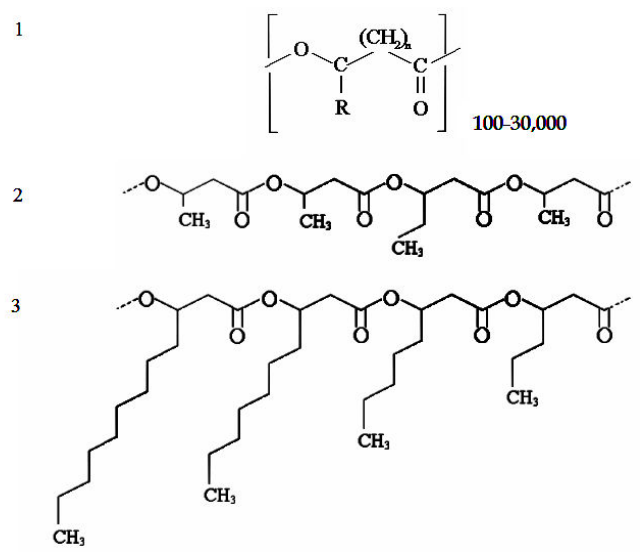

Fig. 2: Chemical structures of PHAs.

1) General structural of PHAs. 2) The copolymer poly(3-hydroxybutyrate-co-3hydroxyvalerate) $\mathrm{P}(3 \mathrm{HB}-c o-3 \mathrm{HV})$ as example of SCL. 3) $\mathrm{P}(\mathrm{HHX}-\mathrm{co}-\mathrm{HO}-\mathrm{co}-\mathrm{HD}-$ co-HDD-co-.....) as an example for MCL.

\section{PHAS CHEMICAL STRUCTURE}

Like any polymer, PHAs are chains of monomers repetition either homopolymer or heteropolymer. In general, PHAs known to be linear, are composed of 3-hydroxy alkanoic acid monomers units, each unit form an ester bond with the hydroxyl group of the other one. The hydroxyl-substituted carbon atom has $R$ configuration in all characterized PHAs. At the $\mathrm{C}-3$ atom ( $\beta$ position), an alkyl group which length can vary from methyl $(\mathrm{C} 1)$ to tridecyl (C13) is located as in Fig. 2 [48]. This alkyl side chain is not necessarily saturated. Unsaturated, aromatic, epoxidized, halogenated, and branched monomers have been reported as well [21, 58 - 66]. By cross-linking of unsaturated bonds substations in the side chains of PHAs, for instance, can be added chemically [67].

Lütke-Eversloh et al was the first report to produce biopolymers with thioester linkages in the polymer backbone using $C$. necator in media containing 3mercaptopropionate (3MP) or 3-mercaptobutyrate (3MB) in addition to 3-hydroxybutyrate as constituents $[16,17]$.

Many factors affect the PHAs chemical composition like the microbial strain, the substrate, the cultivation condition, the extraction method, the number of phaC, phaB genes, the regulator phaP (phasin) and the presence of inhibitors. They inhibit different pathways especially those, which supply the synthases with different kinds of monomer or inhibit other pathways, which consume these monomers for their own or degrade it to shorter units like $\beta$ oxidation pathway.

The $\mathrm{PHA}_{\mathrm{MCL}}$ is synthesized with an average molar mass ranging from $5 \times 10^{4}$ to $2 \mathrm{x}$ $10^{5} \mathrm{~g} / \mathrm{mol}$, whereas PHB can be produced with an average molar mass of $>1 \times 10^{6} \mathrm{~g} / \mathrm{mol}$. In general, the PHA composition depends on the PHA synthases, the carbon source and the metabolic routes involved $[19,68]$.

PHAs' molecular weights have been established by light scattering, gel permeation chromatograph and sedimentation analysis. Their monomer composition has been 
determined by gas chromatography (GC), mass spectroscopy (MS) and nuclear magnetic resonance (NMR) analysis [16, 17, 44].

\section{PHAS PHYSICAL PROPERTIES}

PHAs' crystal structure, polydispersities, melting point, enthalpy of fusion, glass transition temperature and mechanical properties were established by the use of different procedures. PHAs, ranging from stiff, brittle to rubber-like make them a close substitute for the synthetic plastic. PHB, compared with plastic like polypropylene, is considered as having the most common properties [69], and PHB was in fact a thermoplastic [70] as presented in Table 1.

In the case of PHB-within the cell it exists in a fluid, amorphous state. However, after extraction from the cell with organic solvents, PHB becomes crystalline and rigid but brittle material [71]. The brittleness of PHB during mechanical processes makes it unresisting to stress. The major problem of PHB is that it decomposes near its melting point. However, if there is another monomer included in the structure of PHB such as $3 \mathrm{HV}$ it decreases PHB crystallinity and increases its elasticity [72].

The rubber or latex-like $\mathrm{PHA}_{\mathrm{MCL}}$ exhibits physical properties significantly different from the $\mathrm{PHA}_{\mathrm{SCL}}$ with respect to the melting temperature and the extension at the break point as in Table 1.

Table 1: Properties of some PHAs and polypropylene

\begin{tabular}{|c|c|c|c|c|c|}
\hline Parameter & $\mathrm{P}(3 \mathrm{HB})$ & $\begin{array}{l}\mathrm{P}(3 \mathrm{HB}- \\
c o-3 \mathrm{HV})\end{array}$ & $\begin{array}{l}\mathrm{P}(3 \mathrm{HB}- \\
c o-4 \mathrm{HB})\end{array}$ & $\begin{array}{l}\mathrm{P}(3 \mathrm{HO}-\mathrm{co}- \\
3 \mathrm{HH})\end{array}$ & PP \\
\hline$T_{m}\left({ }^{\circ} \mathrm{C}\right)$ & 177 & 145 & 150 & 61 & 176 \\
\hline$T_{g}\left({ }^{\circ} \mathrm{C}\right)$ & 2 & -1 & -7 & -36 & -10 \\
\hline Crystallinity (\%) & 70 & 56 & 45 & 30 & 60 \\
\hline $\begin{array}{l}\text { Extension at break } \\
(\%)\end{array}$ & 5 & 50 & 444 & 300 & 400 \\
\hline
\end{tabular}

\section{LIMITATIONS OF PHAS COMMERCIALIZATION}

The production cost of PHAs is the main commercialization-limiting factor for these biopolymers. PHAs' accumulation requires special growth conditions and it's usually imbalanced nutrition that causes slow growth.

The Imperial Chemical Industries in Billingham, United Kingdom produced copolymers of PHB-co-PHV on a large scale [69]. The market penetration is rather scarce, 
and the products are known as "Biopol" trademark. In 1990, the German company Wella used Biopol-made flasks for a new shampoo. Bacteria-produced PHA is approximately, five to ten times more expensive than its competitors, polypropylene or polyethylene. Although this natural product is promising, its price at that time was $\$ 17$ to $\$ 22 / \mathrm{kg}$ [73]. The market price of Biopol prepared by ZENECA BioProducts, a subsidiary company of ICI, was about $\$ 16 / \mathrm{kg}$. Development of better fermentation and purification technologies and the use of genetic engineering lowered the price, which becomes $\$ 4 / \mathrm{kg}$, but it is still expensive compared to its competitors.

Major expenses in the production of PHA are determined by the cost of the fermentation substrates, and the extraction of the polymer from the cells [69]. Another trill for PHAs commercialization was started in 1996, when the American company Monsanto bought the Biopol material from ZENECA BioProducts. Monsanto tried to produce Biopol by using transgenic plants. The genes originating from bacteria were transferred to plants by genetic engineering methods, which produce the polymer. Monsanto was optimistic about the PHAs commercialization researches especially those concerning the transgenic soya and oilseed rape. Unfortunately, Monsanto has terminated its project in late 1998. Developing countries did not have enough experience in the field, but had other positive factors to overcome PHAs production cost like cheap raw material resources and available work forces [74].

Yamane et al. reported that the major cost in PHA production is their substrate [75]. It is important to highlight that if microbial cells in their optimum condition are able to accumulate PHA it will not exceed certain limit based on their size capacity. Unfortunately, usually big microbial cells have lower generation time. The cheapest substrate cost is $\$ 0.22 / \mathrm{kg}$ of PHA while the cost of polypropylene is $\$ 0.185 / \mathrm{kg}$ [76]. The substrate cost affects the overall cost but the cheapest substrate is not always the ideal choice. When the PHB productivity increased from 1.98 to $3.2 \mathrm{~g} / \mathrm{h}$, the PHB production cost decreased from $\$ 5.37 / \mathrm{kg}$ to $\$ 4.91 / \mathrm{kg}$ [77]. In a laboratory fed-batch system using $A$. latus, the highest reported productivity was $4.94 \mathrm{~g} / \mathrm{h}$ with cost about $\$ 2.6 / \mathrm{kg}$ [77].

Amara and Salem were describing phenol degradation using microbial strains have the PHA production system which could be used for PHAs production during phenol degradation process [78].

\subsection{Why are PHAs Still so Attractive?}

Scientists and industrialists have been looking for a replacement of petroleum plastic, which causes a lot of environmental, health, biodiversity and economic problems with a more safe type of plastics, which are bio-friendly. PHB, and other member of PHAs family provide the hope as a solution to those problems with petroleum plastic. PHAs are biodegradable without any toxicity, bio-evaluable and to some extent do not make any stimulation to the human immune system even if the human body can degrade the polymer after a period of time. This will match the request of many medicinal and pharmaceutical applications. 


\section{PHAs APPLICATIONS}

\subsection{Industrial Applications}

The first potential application of PHAs polymers was recognized in the 1960s [79]. PHAs patents cover a wide range of PHAs products such as coating and packaging, bottles, cosmetic containers, golf tees, and pens [80 - 82]. PHB alone or with $3 \mathrm{HV}$ as a copolymer have been used as diaper back sheets and films [83, 84]. PHAs have also been processed into fibers, for a nonwoven fabrics material [85]. PHB and PHB-co-PHV have been used as hot-melt adhesives [86]. PHAs are used as developer compositions and toner or in ion-conducting polymers [87, 88]. PHAs are used as latex in paper-coating applications, [89], in dairy cream substitutes [90], in food flavour delivery agents [91], or as raw materials for the synthesis of enantiomerically pure chemicals and paints [23, $92-$ 96]. PHAs are also used in packaging materials or agricultural foil [97]. To produce a coating, the PHA latex is sprayed onto a substrate such as paper. After the evaporation of water, the PHA latex particles readily coalesce into a film [67]. PHA might also find marine applications, such as in fishing nets $[98,99]$.

Aiming to widen the range of industrial applications and establishing a method for changing PHAs compositions as well as PHAs' overproduction Amara et al., described a new simple strategy for in vivo random mutagenesis and mutants selection using synthase gene from Aeromonas punctata employing the mutator strain Escherichia coli XL1-Red and Nile red plates. The mutants mediated synthesis of PHAs with an increased weight average molar mass. Mean while the molar percentage is different which an early indication about the possibility of changing the substrate specificity using random mutagenesis. In vivo random mutagenesis proved to be a versatile tool to isolate mutants exerting improved properties with respect to PHA biosynthesis [100, 101].

Taguchi et al., used another strategy based on in vitro mutagenesis for $p h a C_{R e}$ using PCR [102, 103].

\subsection{Biomedical Applications}

Due to the relatively high cost of PHAs production, it's wise to apply PHAs for some cost effective applications like medicinal instruments.

PHAs have been proved biocompatible in tissue engineering, implantations, etc. Many prokaryotic and eukaryotic organisms are able to produce low molecular weight PHB molecules that are complexed with other biomolecules such as polyphosphates and that are present at low concentrations [104].

Over the past years, PHAs were used to develop many devices and material useful for clinical purposes such as sutures fasteners, meniscus repair devices, rivets, tacks, staples, screws, (including interference screws), bone plates and bone plating systems, surgical mesh, repair patches, orthopedic pins (including bone filling augmentation material), adhesion barriers, stents, guided tissue repair regeneration devices, articular cartilage repair devices, nerve guides, tendon repair devices, pericardial patches, bulking and filling agents, vein valves, bone marrow scaffolds, meniscus regeneration devices, ligament, 
tendon grafts, ocular cell implants, spinal fusion cages, skin substitutes, dural substitutes, bone graft substitutes, bone dowels, wound dressing and hemostats [105 - 111].

To assess the biocompatibility of PHB, the structural organization of cellular molecules involved in adhesion was studied using osteoblastic and epithelial cell lines. On PHB, both cell lines revealed a rounded cell shape due to reduced spreading. The filamentous organization of the actin cytoskeleton was impaired. In double immunofluorescence, analyses the co-localization of the fibronectin with the fibril actin was demonstrated [112]. The investigated properties of PHB and PHB-co-PHV films proved to be fundamentally similar [113 - 117]. PHB-co-PHV film was chosen as a temporary substrate for growing retinal pigment epithelium cells as an organized monolayer before their subretinal transplantation. The surface of the PHB-co-PHV film was rendered hydrophilic by oxygen plasma treatment to increase the reattachment of D407 cells on the film surface. The cells were also grown to confluency as an organized monolayer suggesting PHB-co-PHV film as a potential temporary substrate for subretinal transplantation to replace diseased or damaged retinal pigment epithelium [118].

Tesema et al. and Malm et al. implanted PHB nonwoven patches as transannular patches into the right ventricular outflow tract and pulmonary artery in 13 weanling sheep [119 - 122]. It is concluded that PHB nonwoven patches can be used as a scaffold for tissue regeneration in low-pressure systems. The regenerated vessel had structural and biochemical qualities in common with the native pulmonary artery [122]. PHAs have been used in tissue engineering, as antibiotic carrier, and many other medicinal applications $[123,124,125]$.

Chen and $\mathrm{Wu}$ recently reported that PHAs possesses the biodegradability, biocompatibility and thermo-processibility for not only implant applications but also controlled drug release uses. PHAs show a promising future in pharmaceutical application such as drug delivery, which open a new approach. The many possibilities to tailor-made PHAs for medical implant applications have shown that this class of materials has a bright future as tissue engineering materials [126].

\section{PHAs DETECTION}

\subsection{Detection Using Stains}

Sudan black, Nile blue and Nile red can be easily used for PHAs detection [74, 127, $128,129]$. Nile red is the most common stain used for screening of PHA accumulating bacteria [129]. Amara et al, described a very simple method using Nile red, it depends on the appearance of a clear red color if the colonies on plates are incubated at $-4{ }^{\circ} \mathrm{C}$ for appropriate time [74] as illustrated in Fig. 3 and 4. 


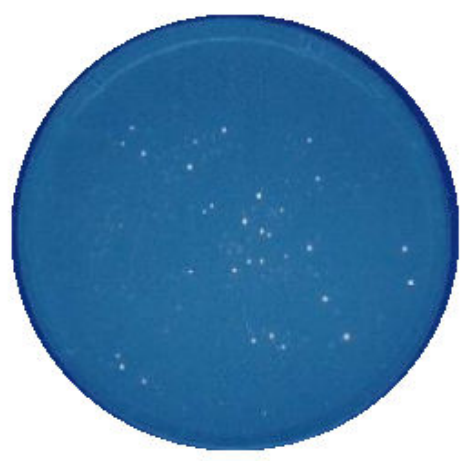

Fig. 3: Agar plate shows fluorescent colonies, which indicate the presence of PHA after visualization by $\mathrm{UV}$ at $312 \mathrm{~nm}$ [74].

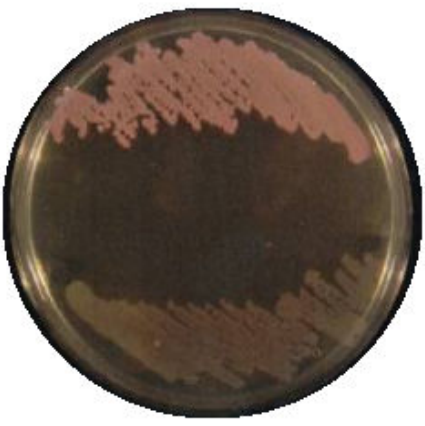

Fig. 4: Nile red plate after incubation at $-4{ }^{\circ} \mathrm{C}$. The red colonies shows the +ve PHA accumulation while the white colonies show -ve PHA accumulation [74].

\subsection{Quantitative Analysis of PHA using GC/MS}

One simple method has been described by Brandl et al. using GC (Gas Chromatography) to analyze various PHAs and further described in detail by Timm and Steinbüchel, $[130,131]$. The amount of PHAs should be calculated based on their different monomeric compositions, eg. if $3 \mathrm{HB}$ and $3 \mathrm{HHx}$ (3-hydroxy-hexanoate) have the same area the amount of PHB monomer will be bigger because it has the lower molecular weight.

\section{BIOCHEMICAL ASPECT ABOUT PHAS BIOSYNTHESIS}

\subsection{PHA Synthases}

PHA synthases are the key enzymes of PHA biosynthesis. PHA synthases use coenzyme A thioesters of hydroxyalkanoic acids (HA) as substrates and catalyze the polymerization of HAs into PHA with the concomitant release of CoA. Twenty years ago in three different laboratories, PHA synthase operon of $C$. necator has been cloned [132, $133,134]$. 


\subsection{PHA SCL $_{\text {Biosynthesis }}$}

PHB is the most extensively investigated PHAs. The PHB biosynthesis pathway consists of three distinct enzymatic reactions. Examination of the enzymes leading to the formation of PHB has shown that the regulation of PHB synthesis is controlled by acetylcoenzymes A (CoA) acyltransferase $[135,136]$. PHB is synthesized from acetyl coenzyme-A (acetyl-CoA) by a sequence of three enzymatic reactions. Synthesis of PHB is believed to be controlled by the first enzyme, 3-ketothiolase that is inhibited by coenzyme A (CoASH) [137].

(i) $\beta$-ketoacyl-CoA thiolase (encoded by phaA)

The first reaction comprises the condensation of two acetyl coenzyme A molecules into acetoacetyl-CoA by $\beta$-ketoacyl-CoA thiolase ( $\beta$-ketothiolase).

(ii) NADPH-dependent acetoacetyl-CoA dehydrogenase (encoded by phaB)

The second reaction is the reduction of acetoacetyl-CoA to $(R)-3$-hydroxybutyryl-CoA by an NADPH-dependent acetoacetyl-CoA dehydrogenase.

(iii) PHB synthase (encoded by phaC)

Finally, the (R)-3-hydroxybutyryl-CoA monomers are polymerized to PHB by PHB synthase.

Under balanced growth conditions, acetyl-CoA is fed into the tricarboxylic acid cycle and the resultant CoA inhibits acetyl-CoA acyltransferase and PHB synthesis. Under nutrient limitation (e.g., Oxygen limitation) and carbon excess, NADH oxidase activity decreases, NADH increases and inhibits citrate synthase and isocitrate dehydrogenase, and acetyl-CoA acyltransferase by $\mathrm{CoA}$ is overcome. The ensuing condensation reaction forms acetoacetyl-CoA and initiates PHB synthesis $[135,136]$. The high NADH/NAD ratio caused oxygen limitation rapidly readjusts as PHB synthesis starts, and PHB assumes the role of an alternative electron acceptor [135].

The degradation of PHB is initiated by PHB depolymerase to form $\mathrm{D}(-)$ hydroxybutyric acid. An NAD-specific dehydrogenase oxidizes the acid to acetoacetate, which is an intermediate common to the biosynthesis and degradation of PHB [99].

\section{3 $\quad$ PHA $_{\text {MCL }}$ Biosynthesis}

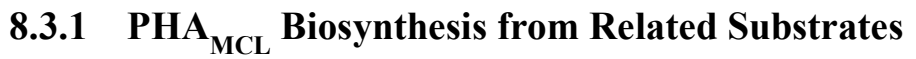

In 1983, De Smet described the accumulation of PHA, the PHA $\mathrm{MCL}_{\text {, }}$, in Pseudomonas oleovorans grown on octane as sole carbon source [45]. The compositions of the PHAs formed by pseudomonads of the rRNA homology group I were directly related to the structure of the alkane, alkene or fatty acid used as carbon source [46, 130]. These substrates are referred to as 'related substrates'. When the carbon source consists of fatty acids with 6 to 12 carbon atoms, monomers of the PHA are of the same length as the carbon source or are shortened by 2,4 or 6 carbon atoms. 


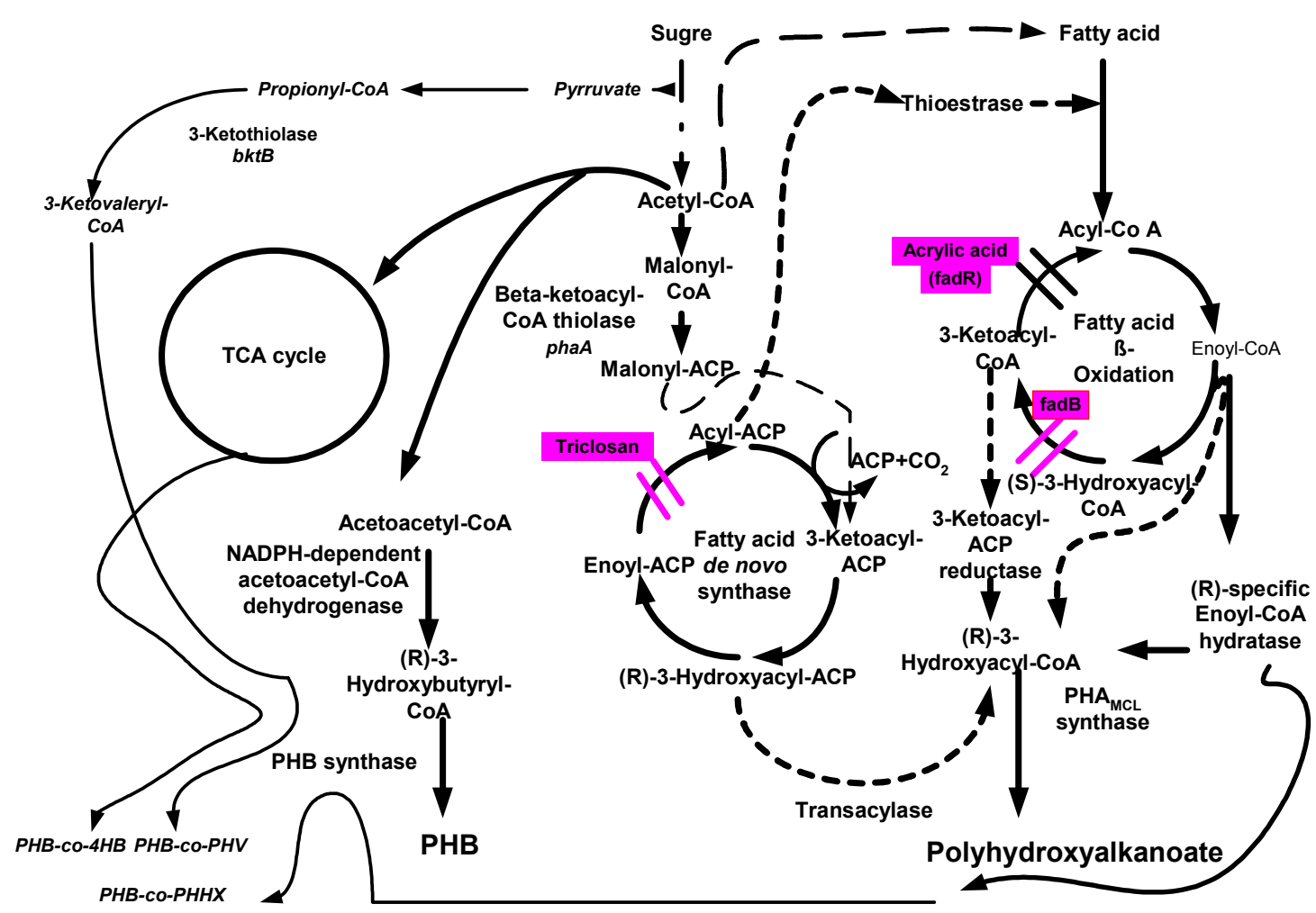

Fig. 5: Metabolic pathways leading to the biosynthesis of PHAs, PHB, PHB-co-PHV, co-4HB, -co-PHX, $\mathrm{PHA}_{\mathrm{MCL}}$. Acrylic acid is the inhibitor of fatty acid $\beta$-oxidation pathway and triclosane is the inhibitor of fatty acid de novo biosynthesis pathway.

Aeromonas punctata produces a random copolymer of $3 \mathrm{HB}$ and $3 \mathrm{HHX}$, when growing on even-numbered fatty acids or olive oil as sole carbon source. PHA production in $A$. punctata proceeds from the $\beta$-oxidation pathway intermediate 3-hydroxyenoyl-CoA, which is hydroxylated by the enantiospecific enoyl-CoA hydratase (Fig. 5).

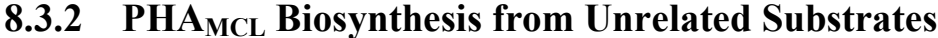

Synthesis of PHAs other than PHB which are not related to their growth substrates occur relatively rarely in Nature [22]. These substrates, which do not resemble the monomers of the accumulated polymer, are named "unrelated substrates".

The PHAs production under unbalanced conditions is highly naturally engineered. The first indication about the ability of synthases to utilize products from other pathways in their monomeric composition was reported by Wallen and Rohwedder in 1974 who, reported heteropolymers of $\mathrm{HB}$ and 3-hydroxyvalerate in chloroform extracts of activated sewage sludge as major constituents with $\mathrm{C} 6$ and possibly $\mathrm{C} 7$ 3-hydroxyacids as minor components [43]. Slater et al., identified that a second $\beta$-ketothiolase gene in $C$. necator is responsible for synthesis of 3-ketovaleryl-CoA [138]. 
Pseudomonads of the rRNA homology group I like $P$. putida KT2442, accumulate PHAs that consist primarily of $\mathrm{C} 10$ and $\mathrm{C} 8$ monomers, when grown on sugars or gluconate $[131,139]$. These monomers are derived from intermediates of fatty acid biosynthesis and the composition of the PHAs is a reflection of the pool of fatty acid biosynthetic intermediates.

\subsubsection{Metabolic Engineering of PHA}

\subsubsection{Linking Metabolic Pathways}

Different PHAs could be produced from simple cheap carbon sources; alternatively, the carbon source may be derived from waste materials like whey lactose, coals and methane. Steinbuchel in 2001 mentioned that in order to produce PHAs other than PHB from $\mathrm{CO}_{2}$ or renewable resources it will be necessary to link central metabolic pathway with PHA synthesis [15].

Rehm et al., determined that the gene product of phaG, $(R)$-3-hydroxyacyl-ACP:CoA transacylase, is responsible for the conversion of $(R)$-3-hydroxyacyl-ACP to $(R)-3$ hydroxyacyl-CoA [140]. Another example, the citric acid cycle for generating PHA precursors in recombinant $E$. coli; a polymer consisting of 4-hydroxybutyrate (4HB) was produced by drawing succinyl-CoA from the citric acid cycle, which is converted to 4hydroxybutyryl-CoA, a precursor for PHA biosynthesis [141] as illustrated in Fig. 5.

\subsubsection{Examples of Metabolic Engineering}

Wild type $P$. putida is able to produce PHA $_{\mathrm{MCL}}$ from related and unrelated substrates [related $=$ eg. fatty acid, unrelated $=$ eg., glucose or gluconate] $[46,130,131,139]$. An isolated $P$. putida mutant can grow on any carbon source tested and was able to synthesize PHA $_{\mathrm{MCL}}$ from fatty acids but not from gluconate or glucose [140]. Biochemical studies on the affected enzyme revealed that these enzyme catalyses the transfer of $(R)$-3hydroxydecanoyl moieties from the acyl carrier protein: coenzyme A transferase. The respective gene, which complemented the mutant, was referred to as phaG [140], this one has been also identified and cloned from P. aeruginosa [142] and P. oleovorans [143] (Fig. 5).

In the presence of the substrate, $(R)$-3-hydroxyacyl-CoA the transacylase appeared in apparent molecular weights of $45.4,83.7$ and $102 \mathrm{kDa}$, which indicated substrate-induced conformational changes and oligomerization of the transacylase [144].

\subsubsection{Metabolic Engineering using $E$. coli fadB Mutants}

In E. coli fadB mutant LS1298, the dehydrogenase function is defective, whereas the hydratase and also the epimerase function of FadB remain active [145]. When the fadB mutant LS1298 of E. coli harboring phaC1 was used for PHA biosynthesis, PHAs were accumulated to a significant level, contributing to $20-25 \%$ of the cell dry matter [146]. Obviously, $(S)$-3-hydroxyacyl-CoA accumulates in the cytoplasm of the mutant cells to a level that is sufficiently high enough to be effectively converted into the $(R)$-stereoisomer 
and subsequently incorporated into PHA. Instead of phaC1, phaC2 of P. aeruginosa was also used, and very similar results were obtained [147].

The length of the incorporated 3-hydroxyalkanoic acids reflected the length of the carbon chain of the fatty acid provided as carbon source [147]. The fadBA $P_{O}$ operon and a class II PHA synthase gene of $P$. aeruginosa were heterologously co-expressed in $E$. coli. FadBA $_{P o}$ did not mediate PHA $_{\mathrm{MCL}}$ biosynthesis in $E$. coli wild type strain harboring a PHA synthase gene when cultivated on fatty acids as carbon source. However, PHA accumulation was strongly impaired in a recombinant $E$. coli fadB mutant, which harbored a PHA synthase gene. These data indicates that pseudomonads FadBA does not possess the inherent property, based on a putative epimerase function, to provide the $(R)$ enantiomer of 3-hydroxyacyl-CoA efficiently and that other linking enzymes are required to efficiently channel intermediates of $\beta$-oxidation towards $\mathrm{PHA}_{\mathrm{MCL}}$ biosynthesis [148].

\subsubsection{4 (R)-Specific Enoyl CoA Hydratase}

In A. punctata, a $(R)$-specific enoyl-CoA hydratase is responsible for the conversion of trans-2-enoyl-CoA to $(R)$-3-hydroxyacyl-CoA during the cultivation of this bacterium on e.g. hexanoate [149]. Two $(R)$-specific enoyl-CoA hydratase genes were also identified in $P$. aeruginosa [150]. Studies in recombinant strains of $E$. coli provided evidence that fabG of fatty acid de novo synthesis, which is a 3-ketoacyl-ACP reductase, is non-specific and exhibits activity with the corresponding CoA-thioesters [151]. On the other hand, it was shown that recombinant strains of $E$. coli could also use their own $\beta$-ketothiolase (FadA) in combination with the acetoacetyl-CoA reductase (PhaB) of $C$. necator for the conversion of fatty acids into $\mathrm{PHA}_{\mathrm{MCL}}[152]$ Figure 5.

\subsubsection{Metabolic Engineering using Inhibitors}

Steinbüchel described six chemicals, which specifically inhibit one or other reactions that affect PHAs production [15]. Whereas acrylic acid [153] inhibits the $\beta$-ketothiolase of the $\beta$-oxidation pathway, thiolactomycin [154], 3-decenoyl-N-acetylcysteamine [155], triclosan [156] diazaborine [157], and cerulenin [158] inhibit enzymes of the fatty acid de novo synthesis pathway.

A different system for the production of $\mathrm{PHA}_{\mathrm{MCL}}$ by E. coli was described using acrylic acid as inhibitor [159]. When recombinant strains of E. coli, expressing either phaCl or phaC2 from $P$. aeruginosa were cultivated on fatty acids such as decanoic acid and in the presence of low concentrations of acrylic acid, PHAs were found to be accumulated in all investigated strains of E. coli [159].

Acrylic acid and cerulenin were applied to investigate the competition of the pathways for PHB-co-PHV and triacylglycerol (TAG) biosynthesis in species of the genus Rhodococcus [160]. Acrylic acid completely inhibited the accumulation of TAGs from valerate and caused a two-fold increase in the PHA content which consisted exclusively of $3 \mathrm{HV}$ [160].

Antonio et al., and Amara et al., produced 3HB-3HHX from cultivation of recombinant E. coli on fatty acid using PhaC class I and acrylic acid [101, 161]. 


\section{IN VITRO BIOSYNTHESIS OF PHAS}

Gerngross and Martin have first demonstrated in vitro biosynthesis of PHA and selfassembly of spherical granules by only using purified polyester synthase and substrate [162]. Poly(3HB) was also synthesized by employing the PHA synthase of $A$. vinosum in combination with the auxiliary enzymes propionyl-CoA transferase from Clostridium propionicum alone or with an acetyl-CoA synthase of Saccharomyces cerevisiae [163].

In vitro PHA biosynthesis was achieved using purified PHA synthases alone or together with additional auxiliary enzymes purified from various sources. The auxiliary enzymes over purified ones help to use substrates other than coenzyme A thioesters of hydroxyalkanoic acids and to recycle coenzyme A, which must then be used only in catalytic instead of stoichiometric amounts.

PHB was synthesized from 3-hydroxybutyryl-CoA using the PHA synthases from $C$. necator [162, 164] or A. vinosum [165]. PHV was synthesized from 3-hydroxyvalerylCoA using the PHA synthase of $C$. necator [166].

Homopolyesters and copolyesters of various SCL poly(HA $\left.\mathrm{HAL}_{\mathrm{SCL}}\right)$ such as $3 \mathrm{HB}, 4 \mathrm{HB}$; and 4-hydroxyvalerate (4HV) were synthesized by employing the PHA synthase of $A$. vinosum plus the butyrate kinase and the phosphotransbutyrylase of Clostridium acetobutylicum as auxiliary enzyme [167].

PHD was synthesized by using the PHA synthase PhaC1 of $P$. aeruginosa plus an acylCoA synthase of Pseudomonas sp. [168].

\section{PHA PRODUCTION IN YEAST}

Reush, 1989 describes an evidence of PHB existing in yeast and many other eukaryotic cells, which contain small amount of low molecular mass PHB, which function as complexes with polyphosphate in membrane transport [169].

Expression of the $C$. necator PHB biosynthetic pathway was successfully achieved in the yeast Saccharomyces cerevisiae by Leaf et al., who reported that the expression of PHB synthase in the yeast cytoplasm is sufficient for PHB accumulation and that wild type yeast synthesis D-3HB-CoA could rise from intermediates in fatty acid synthesis or through $\beta$-oxidation [170]. Yeast cells can be used as models to gain information about PHAs synthesis in eukaryotes [171]. It is confirmed that three thiolase exist in $S$. cerevisiae functioning in mitochondria, cytoplasm [172] and peroxisomes [173]. Safake et al, in their study succeeded to isolate PHB producing wild type yeast strain from Kombucha tea and reported that the amount of PHB is less than that from prokaryotic and the PHB amount depend upon the type of culture and species [174].

Synthesis of $\mathrm{PHA}_{\mathrm{SCL}}$ was established in the peroxisome of a wild-type yeast strain by targeting the $C$. necator ${ }_{\mathrm{SCL}}$ polymerase to the peroxisome [175].

\section{PHAs PRODUCTION BY TRANSGENIC PLANTS}

Plants are interesting targets for production of the biopolyesters. Transgenic plants could produce PHAs directly from $\mathrm{CO}_{2}$ and solar energy [176]. The biosynthesis of PHB 
in transgenic Arabidopsis thaliana was already reported [3]. Later, the C. necator PHB biosynthesis genes were also expressed in agricultural crops such as Brassica napus [177], Gossypium hirsutum [178] and Nicotiana tabacum [179]. The copolyester PHB-co-PHV [180] and PHAs consisting of $3 \mathrm{HA}_{\mathrm{MCL}}[181]$ have been produced in plants.

\section{ORGANIZATION OF PHA SYNTHASE GENES}

The PHA biosynthesis genes and genes for other proteins related to the metabolism of PHA remain in cluster in bacterial genomes. In $C$. necator, the genes for PHA synthase $(p h a C), \beta$-ketothiolase $(p h a A)$ and the NADP-dependent acetoacetyl-CoA dehydrogenase (phaB) constitute the phaCAB operon [132, 134, 138]. Approximately $4 \mathrm{kbp}$ downstream of this operon a second $\beta$-ketothiolase gene $(b k t B)$ was identified [138]. In Zoogloea ramigera, Methylobacterium extorquens, Sinorhizobium meliloti 41, Nocardia corallina, R. ruber, Paracoccus denitrificans, Rhodobacter sphaeroides, Rhodospirillum rubrum Ha, Rhodobacter capsulatus and Aeromonas punctata phaC seem to be separated from other pha genes.

phaA, phaB or other genes related to PHA metabolism are not directly linked to the phaCs genes in these genomes. In contrast, the gene encoding an enoyl-CoA hydratase in A. punctata is located downstream of phaC. P. oleovorans, Pseudomonas sp. 61-3 and $P$. aeruginosa posses two different phaC genes, which are in the genome separated by the structural gene for an intracellular PHA, depolymerase. Pseudomonas sp. 61-3 contains also these two $p h a C$ genes in addition to another $p h a C$ gene, which is co-localized with phaB and phaA.

In all bacteria, which posses a two-component PHA synthase, phaC and phaE are directly linked in the genomes constituting most probably single operons. In Allochromatium vinosum phaA and phaB are located on the opposite direction in a gene cluster related to PHA metabolism. The organization of the genes is most probably similar if not identical in Thiocystis violacea and Thiocapsa pfennigii, whereas in Synechocystis $s p$. PCC 6803 further pha genes do not map close to the phaEC locus. In R. ruber and $A$. vinosum the structural genes for phasin proteins (ORF3 and ORF5, respectively) map close to the respective phaC loci [182].

\section{PRIMARY STRUCTURES OF PHA SYNTHASES, CLASSES AND SUBSTRATE SPECIFICITY}

PHA synthases are classified into four classes based on their substrate specificity and subunits composition. The class I PHA synthases, with $C$. necator synthase as prototype, is composed of one single type of polypeptide chain and use mainly $(R)$-3-hydroxybutyrylCoA, $(R)$-3-hydroxyvaleryl-CoA and other SCL hydroxyalkanoic acid CoA thioesters including 3-mercaptoalkanoic acid CoA thioesters as substrates [16, 182]. The class III PHA synthases, as represented by the $A$. vinosum enzyme, is composed of two different subunits each of about $40 \mathrm{kDa}$ [183]. The substrate specificity is similar to that of class I synthases, although some medium chain length 3-hydroxyfatty acids are also incorporated [184]. 
Both classes (I and II) of PHA synthases were purified, and in vitro activity has already been achieved $[162,163,185,186]$. The class II enzymes, which are composed of only one type of subunit, are mainly found in pseudomonads such as $P$. aeruginosa. One major difference between class II and both, class I and III PHA synthases is the substrate specificity. Class II PHA synthases incorporate preferentially 3-hydroxyfatty acids of MCL (C6-C14) into PHAs, and the resulting product is a latex-like polymer [147, 159]. These substrates are mainly derived from intermediates of fatty acid $\beta$-oxidation or from fatty acid de novo biosynthesis [140 - 143, 188] provided fatty acids or simple non-related carbon sources [141]. Class II PHA synthases were purified and in vitro activity was achieved $[189,190]$. An amino acid sequence alignment showed that the $A$. vinosum PHA synthase revealed high homology to prokaryotic lipases whose crystal structures are known. The amino acid Ser at the active site of the lipase did align with the Cys at the active site of the PHA synthase. A threading model of the A. vinosum PHA synthase was generated [191]. Accordingly, a threading model of the class II PHA synthase from $P$. aeruginosa was developed [192] and based on the homology to the structure of the lipase from B. cepacia. Rehm et al. developed threading model for PHA synthase from $C$. necator based on the alignment of the $C$. necator PHA synthase $\left(\mathrm{PhaC}_{R e}\right)$ with the Burkholderia glumae lipase (1TAH_A) [193].

In the multiple alignment of PHA synthases only one Cys residue (Cys-319) is highly conserved. Therefore, scientists are looking since several years for the second thiol group. The essential role of Cys-319 of the C. necator PHA synthase for the reaction mechanism was obtained from site-specific mutagenesis [185]. The weakly conserved Cys-459 was supposed to be involved in the catalytic cycle, providing the second thiol group. However, site-specific mutagenesis [185] clearly indicated, that this amino acid residue is not essential for catalytic activity. This is fully supported by the alignment of PHA synthase sequences. In position 260 of the PHA synthase from $C$. necator a conserved Ser residue was observed. This Ser-260 was proposed as target for covalent posttranslational modification by 4-phosphopantetheine, which should provide the second thiol group similar to fatty acid synthase. In order to investigate posttranslational modification by 4phosphopantetheine, radiolabeling experiments were conducted, expressing PHA synthase gene from $C$. necator in E. coli SJ16 (panD). Since E. coli SJ16 is $\beta$-Ala auxotroph, specific radiolabeling of 4-phosphopantetheinylated proteins occurs, when cells were fed with 2-14C- $\beta$-Ala. These experiments indicated that the PHA synthase was labeled by 4phosphopantetheine [185].

However, detailed analysis revealed that only a small portion of total PHA synthase was labeled [194]. Functional low level expression of PHA synthases from $C$. necator and $P$. aeruginosa, respectively, in $E$. coli SJ16 and also in $\beta$-alanine auxotrophic mutants of $C$. necator with subsequent analysis of 4-phosphopantetheinylated proteins gave no evidence for covalent posttranslational modification by 4-phosphopantetheine [195]. Exchange of amino acid residue Ser-260 against alanine and threonine, respectively, abolished in vivo and in vitro activity of PHA synthase from C. necator [195]. The current model of active PHA synthase involves two subunits forming a homodimer PHA synthases have been assigned to four classes based on their substrate specificity and subunit composition. The multiple alignments of the primary structures of these PHA synthases showed an overall identity of 9 to $96 \%$ with only 8 strictly conserved amino acid residues [193]. 
Considering class I and II PHA synthases, and forming a heterodimer (PhaC and PhaE) in case of class III PHA synthases. Accordingly, class I and II PHA synthases possess two thiol groups provided by conserved Cys-319, and in class III PHA synthases the second thiol group might be provided by conserved Cys-130 of subunit PhaE from A. vinosum [194].

A novel PHA synthase (class IV) from Bacillus megaterium required $\mathrm{PhaC}_{B m}$ and $\mathrm{PhaR}_{B m}$ for activity in vivo and in vitro was reported [196]. $\mathrm{PhaC}_{B m}$ showed greatest similarity to the PhaCs of class III in both size and sequence. Unlike those in class III, the $40 \mathrm{kDa}$ PhaE was not required, and further more, the $22 \mathrm{kDa} \mathrm{PhaR}_{B m}$ had no homology to PhaE.

Amara and Rehm described seven site directed mutations have been performed in $\mathrm{PhaC}_{\mathrm{Pa}}$ where 5 conserved residues were replaced in order to identify the role of these amino acids in catalysis. The replacement of W398 by alanine abolished PHA $\mathrm{MCL}_{\text {synthase }}$ activity indicating that W398 is essential for enzyme activity [197].

The replacement of $\mathrm{H} 479$ by glutamine did not affect the $\mathrm{PHA}_{\mathrm{MCL}}$ activity, which indicates that $\mathrm{H} 479$ is not the general base catalyst that activates the nucleophilic C296 for covalent catalysis. The replacement of $\mathrm{C} 296$ with serine which is the the general base catalyst in lipases did not abolish PHA $_{\mathrm{MCL}}$ synthase activity while still exhibiting $20 \%$ activity in comparison to the wild type. Replacement of C296 with Ala abolished PHA synthase activity which is a strong evidence that serine may be able to replace Cys as catalytic nucleophile for changing substrate specificity of PHA synthase. For further investigation, another site directed mutagenesis has been done in another conserved histidine (H452), which was replaced with Glu. The H452Q mutant was highly impaired in $\mathrm{PHA}_{\mathrm{MCL}}$ activity, which indicates that $\mathrm{H} 452$ plays a major role as a general base catalyst instead of H479 [197].

Localized semi-random mutagenesis has been used to alter substrate specificity of the class II polyester synthase from P. putida [198]. Recently, Tsuge et al., found that the A510 of the C. necator polyester synthase is involved in substrate specificity [199].

The tertiary structure of PHA synthases has not been resolved by X-ray diffraction analysis, yet. Secondary structure prediction based on the multiple alignment of PHA synthases indicated with an expected accuracy of about $72 \%$, that PHA synthases are mainly composed of variable loop $(49.7 \%)$ and $\alpha$-helical $(39.9 \%)$ secondary structures, whereas for only $10.4 \%$ a $\beta$-sheet structures were predicted [200].

Thus, PHA synthases belong with respect to their predicted secondary structure content to the mixed class of proteins. Purified PHA synthase exists in an equilibrium of monomeric and dimeric forms whereas dimerization is significantly induced in the presence of substrate and of trimeric CoA analogs (3-hydroxybutyryl)3-CoA, respectively. In addition, the enzymatic lag phase is reduced and the specific activity increased in the presence of trimeric analogs [201]. This indicates that the dimeric form is substantially more active than the monomeric form in the absence of the putative primer. Since radiolabeled trimeric CoA analogs were found to be covalently bound to the PHA synthase 
of $C$. necator, the radiolabel resides only the dimeric form as indicated by size-exclusion chromatography [202].

This homogenous population of particles measuring 11.2-12.8 nm in diameter and data derived from gel filtration chromatography indicate that this PHA synthase might be composed of ten subunits [186, 203].

Overall, with respect to quaternary structure of PHA synthases these data suggest that in vitro the active PHA synthase consists of two subunits and that in vivo the PHA synthase associated with PHA granule surface might be composed of ten subunits in $A$. vinosum [192].

\section{PHA BIODEGRADABILITY}

Biodegradation is a process mediated by special enzymes which able to degrade chemical compounds. Without enzymatic degradation, our life will not be imaginable. While depolymerases have been studied for about 40 years, the first structural gene of a PHA depolymerase (Alcaliginus faecalis, pha $_{A f}$ ) was cloned and sequenced only in 1989 by Saito et al. [204]. Depolymerases are highly specific for the polymers consisting of monomers in the $(R)$ configuration [205]. PHAs depolymerase are carboxyesterases (EC 3.1.1) and hydrolyze the water insoluble polymer to water-soluble monomers and/or oligomers and finally to water and carbon dioxide or methane. Early PHB degrading bacteria were isolated by selection for microorganisms able to utilize PHB as the sole source of carbon and energy (Fig. 6) [24]. PHAs degrading bacteria differ from each other depending on the type of PHAs they degrade, however some bacteria revealed a rather broad polyester specificity and are able to utilize a wide range of PHAs [206, 207]. Three intracellular PHA depolymerases (PhaZ1, PhaZ2 and PhaZ3) and a 3HB-oligomer hydrolase (previously designated PhaZ2), which hydrolyse PHAs and the cleavage products produced by PhaZs, were cloned and characterized in C. necator [207 - 210].

Fungi also could degrade PHAs and their depolymerases have been characterized [211, 212]. PHAs depolymerases show a similar characteristic, they are stable at a range of $\mathrm{pH}$, temperature, relatively small $\mathrm{Mr}(<70 \mathrm{kDa})$, they are inhibited by reducing agent, e.g. dithiothreitol (DTT), which indicates the presence of essential disulfide bonds, and by serine hydrolase disulfide bonds, and serine hydrolase inhibitors such as diisopropyl fluorophosphate (DFP) or acylsulfonyl derivatives [212].

Depolymerases have three strictly conserved amino acids: serine, aspartate and histidine. The serine is part of the lipase-box pentapeptide Gly-Xaa1-Ser-Xaa2-Gly [213]. The oxygen atom of the serine side chain is the nucleophile that attacks the ester bond [206, 214].

\subsection{Biotechnological Aspect of PHA Depolymerases}

The production of enantiomer-pure $(R)$-hydroxyalkanoic acids by depolymerasecatalysed hydrolysis of PHA is possible. 
The activities of PHAs depolymerase may vary depending on the composition and the physical form of the polymer (amorphous or crystalline), the environmental conditions and the dimensions of the sample [215 - 218].

While PHA can be produced by different fermentation processes based on agricultural feedstock's derived from $\mathrm{CO}_{2}$ and water, their breakdown products by the activity of depolymerase are again $\mathrm{CO}_{2}$ and water.

Thus, while in some applications the biodegradability is critical, PHAs are good renewable compounds [219].

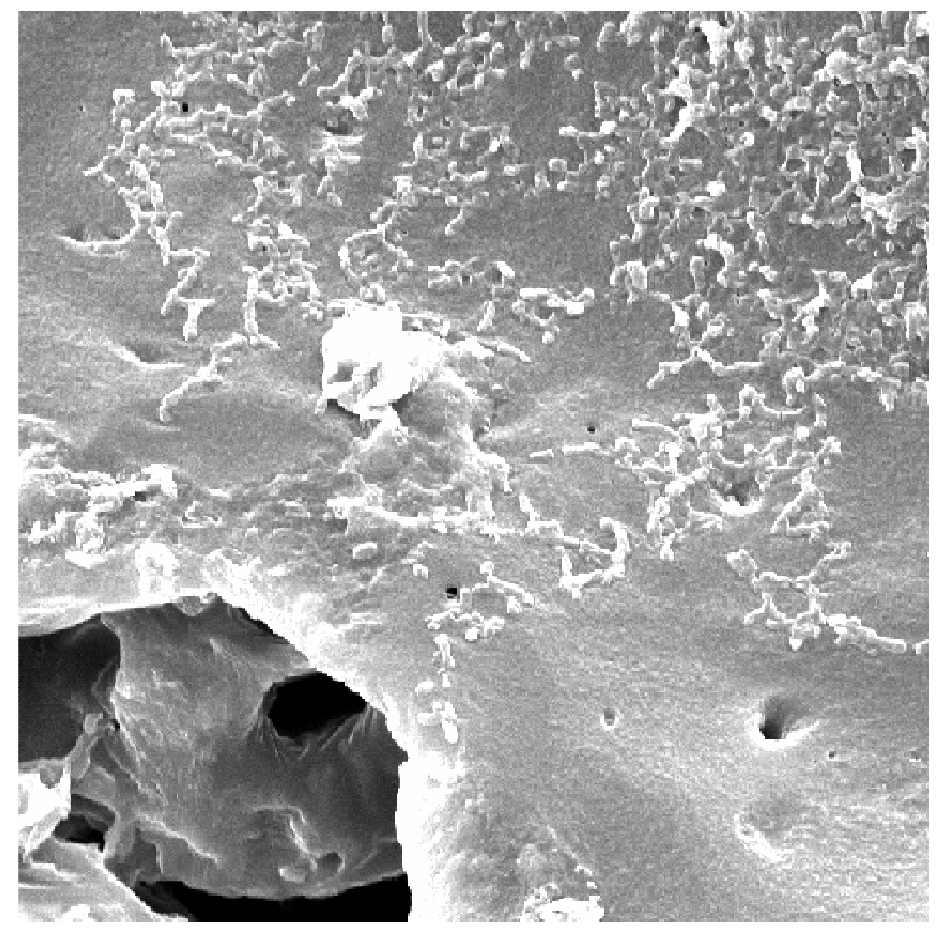

Fig. 6: Scanning Electron Microscope image for PHA surface [2000 x]. The bacterial growth leads to polymer degradation

\section{PHA GRANULES}

PHAs granules are composed of spherical shell-core particles of a PHAs core enclosed by phospholipids and proteins.

In vivo soluble PHAs synthases are changed into amphipathic enzymes upon the elongation of the water-insoluble PHAs chains, which remain covalently attached to the enzyme. A self-assembly process suggested to be initiated and leads to the formation of insoluble cytoplasmic inclusions with a phospholipid monolayer and covalently attached PHAs synthases at the surface. The structural proteins called phasins can be found attached to the granule surface [210, 220, 221]. 
Dunolp and Robards developed the first models for the structure of the inclusion with intriguing observation that this polymer was stretchable even at very low freeze -fracture temperature [222].

It was shown that PHA granules consists of a hydrophobic core of amorphous PHA that is surrounded by a membrane consisting of PHA synthases, the PHA depolymerase, amphiphilic phasin proteins and possible additional proteins. According to one model, these proteins are embedded in or associated with a phospholipid monolayer [221]. According to Byron, about 8 to 13 granules per cell having diameter range of 0.2 to 0.5 found in C. necator [223]. Immunoelectron microscopy studies of granules isolated from A. vinosum, employing gold-labeled anti-PhaC antibodies clearly indicated the presence of PHA synthase complexes at the surface of the PHA granule [189, 203].

Another model outlines a much more complex membrane structure with two phospholipids membranes [224]. NMR analysis provided evidence that water molecules are present in the core structure of the granules and that these molecules function as plasticizer [225]. Thus, the enzyme(s) responsible for PHA biosynthesis and consumption operate only on mobile hydrated material and that the solid granules characteristics of dried cells are partially artifactual.

Pötter et al. described orthologus and paralogous phasins occurring in C. necator. The analysis of the genome sequence of the PHAs accumulating bacterium Ralstonia eutropha (C. necator) strain H16 revealed three homologues (PhaP2, PhaP3 and PhaP4) of the phasin protein PhaP1. PhaP1 is known to constitute the major component of the layer at the surface of PHB granules. PhaP2, PhaP3 and PhaP4 exhibited 42, 49 and 45\% identity or 61,62 and $63 \%$ similarity to PhaP1, respectively [226].

In addition to PHA synthase, PHA depolymerases (PhaZ) are also bound to the PHA granule surface.

The establishment of in vitro polyester synthesis using purified polyester synthases form various microorganism, such as e.g. from $C$. necator, A. vinosum, $P$. aeruginosa (PhaC1 and $\mathrm{PhaC} 2$ ) and $P$. oleovorans (PhaC1) [163, 167, 168, 201, 227] provided a new tool to study the formation of macroscopic PHA granules. In vitro PHA synthesis was firstly achieved using recombinantly produced and purified $C$. necator polyester synthase [162]. The granule formation occurred after only a few minutes when the substrate, $(R)-3-$ hydroxybutyryl coenzyme A, was provided to the purified polyester synthase [228].

\section{PHA FUTURE}

It is clear from the amounts of research performed on PHA indicates that this biopolymer is very promising. What made this kind of polymer has such attraction? It is the PHA properties. PHA is biodegradable, biocompatible and has good mechanical properties. PHA different technological aspects including production, purification, analysis, different applications, changing monomer composition etc., become clear based on the intensive research done concerning PHAs. Every week there is new information about PHAs. The number of publications exceeds most of the current important research topics. 
What makes PHAs especially important is that the petroleum oil price is increasing tremendously and its stock will be ended approximately in this century! It is important for the global community to have a standby solution for the products derived from petroleum oil. PHAs at least will be a solution for most of the industries, which depends on material made from plastics. PHAs are environmentally and human-friendly which will make them more suitable than petroleum-based plastic for many applications. The price of PHAs' production decreases significantly, while at the same time the petroleum oil price is constantly increasing. The gap between the petroleum oil and PHAs prices becomes so close.

PHAs have promising futures in the field of biomaterial. The chemical, physical and biological properties of PHAs become very clear. The in vivo and in vitro production, controlling their monomer composition and the huge amount of their physical, chemical and biological properties increase the number of their applications.

Perhaps, it is suitable nowadays to use PHAs in cost effective products like medical instruments. Interesting progress in PHAs research has been recognized in the last ten years. From the literature, one can see that the developing countries have now an increasing interest in PHAs' researches. It might be useful to gain the benefit from collaborating research aiming to decrease the production cost of PHAs. The developed countries could help a lot for PHAs commercialization, especially those nations that have natural resources as well as the necessary work forces.

Finally, the researchers have made a lot of effort to improve this scientific field. Highlighting the importance of supporting researches on PHA will bring the wealth for all humanity which is one of the aims of this review. PHAs are safe products and green in all points.

\section{ACKNOWLEDGMENTS}

I deeply acknowledge the valuable support and encouragement from Prof. D. Alexander Steinbüchel, Prof. Dr. Hassan Moawed and Prof. Dr. Bernd Rehm especially during my PhD study. Special thanks to Ms Siham Zayer, for some advices during the writing of this review. I acknowledged the DAAD for the financial grants, which supported my research in this field. I also acknowledged others from the Institute fur Molekular Mikrobiologie und Biotechnologie, Universitat Munster, Germany, and Mubarak City for Scientific Research and Technological Applications, Egypt, who have supported me and sharing their knowledge.

\section{REFERENCES}

[1] B. Lee, III. AL Pometto, A. Fratzke, T. B. Bailey, "Biodegradation of degradable plastic polyethylene by Phanerochaete and Streptomyces species". Appl. Environ. Microbiol., vol. 57 pp. 678-685, 1991.

[2] R. B. Cain "Microbial degradation of synthetic polymers". In: Frey et al. (eds) "Microbial Control of Pollution". 48th Symposium of the Society for general microbiology at University of Cardiff, pp. 293-338, 1992. 
[3] Y. Poirier, C. Somerville, L. A. Schechtman, M. M. Satkowski, and I. Noda, "Synthesis of high-molecular-weight poly([R]-(-)-3-hydroxybutyrate) in transgenic Arabidopsis thaliana plant cells". Int. J. Biol. Macromol., vol. 17 pp. 7-12, 1995.

[4] S. Y. Lee, "Bacterial Polyhydroxyalkanoates". Biotechnol. Bioeng., vol. 49 pp. 1-14. (1996).

[5] C. Rivard, L. Moens, K. Roberts, J. Brigham and S. Kelley, "Starch esters as biodegradable plastics: Effects of ester group chain length and degree of substitution on anaerobic biodegradation". Enzyme and Microbial Tech., vol. 17 pp. 848-852,

[6] U. Witt, R. J. Muller, W. D. Deckwer, "Biodegradation behaviour and material properties of aliphatic/aromatic polyesters of commercial importance". J. Environ. Polymer. Degrad., vol. 15 pp. 81-89, 1997.

[7] R. J. Muller, I. Kleeberg, W. D. Deckwer, "Biodegradation of polyesters containing aromatic constituents". J. Biotechnol, vol. 86 pp. 87-95, 2001.

[8] W. Urbaniak Thermal recycling. To burn or not to burn used packages? in: Proc. 2nd Scientific-Instructive Conference "Packaging and Environment Protection". ed. Arka S.A. Konsorcjum Poznan, vol. pp. 107-122, 1998 (in Polish).

[9] W. Urbaniak "Usage of spent plastics packages". Packaging. 6, 23, 1999 (in Polish).

[10] A. Korzeniowski, H. Kubera, "Technical and ecological aspects of development in food industry". Food Industry, vol. 53 (1), 321999.

[11] J.G. B. Derraik, "The pollution of the marine environment by plastic debris: a review". Marine Pollution Bulletin., vol. 44, pp. 842-885, 2002.

[12] D. K. A. Barnes, "Invasion by marine life on plastic debris". Nature, vol. 416 (25 April) pp. 808-809, 2002.

[13] O. Ahlhaus, "New developments and aspects in design and production of polyester bottles for drinks packaging", in: Proc. 11th IGWT Symposion "Commodity Science and Sustainable Development". Vienna, pp. 16-18, 1997.

[14] P. Suriyamongkol, R.Weselake, S. Narine, M. Moloney, S. Shah, "Biotechnological approaches for the production of polyhydroxyalkanoates in microorganisms and plants - A review". Biotechnology Advances, vol. 25, pp. 148-175 November, 2007.

[15] A. Steinbüchel "Perspective for biotechnological production and utilization of biopolymer: metabolic engineering of polyhydroxyalkanoate biosynthesis pathways as a successful example”. Macromol. Biosci., vol. 1 pp. 1-24. 2001.

[16] T. Lütke-Eversloh, K. Bergander, H. Luftmann and A. Steinbuchel, "Identification of a new class of biopolymer: bacterial synthesis of a sulfur-containing polymer with thioester linkages", Microbiology, vol. 147(Pt 1), pp. 11-19, 2001.

[17] T. Lütke-Eversloh, J. Kawada, R. H. Marchessault and A. Steinbuchel, "Characterization of microbial polythioesters: physical properties of novel copolymers synthesized by Ralstonia eutropha”, Biomacromolecules, vol. 3(1), pp. 159-166, 2002.

[18] T. Lutke-Eversloh, K. Bergander, H. Luftmann and A. Steinbuchel, "Biosynthesis of poly(3hydroxybutyrate-co-3-mercaptobutyrate) as a sulfur analogue to poly(3-hydroxybutyrate) (PHB) ", Biomacromolecules, vol. 2(3), pp. 1061-1065, 2001.

[19] L. L. Madison, and G. W. Huisman, "Metabolic engineering of Poly(3-Hydroxyalkanoates): from DNA to plastic". Microbiol. Mol. Biol. Rev., vol. 63 pp. 21-53, 1999.

[20] B Witholt, B. Kessler, "Perspectives of medium-chain-length poly (hydroxyalkanotes), a versatile set of bacterial bioplastics”. Curr. Opin. Biotechnol., vol. 10 pp. 279-285. 2002 
[21] Y. B. Kim, R. W. Lenz, and R. C. Fuller, "Preparation and characterization of poly( $\beta$ hydroxyalkanoates) obtained from Pseudomonas oleovorans grown with mixtures of 5phenylvaleric acid and n-alkanoic acids". Macromolecules, vol. 24 pp. 5256-5360, 1991.

[22] A. Steinbuchel and B. Fuchtenbusch, "Bacterial and other biological systems for polyester production". Trends Biotechnol., vol. 16(10), 419-427, 1998.

[23] P. J. Hocking, and R. H. Marchessault, "Biopolyester in Chemistry and technology of biodegradable polymers'. Griffin, G. J. L. (ed.), Blackie Academic, UK, pp.481994.

[24] A. Chowdhury, "Poly- $\beta$-hydroybuttersäure abbauende Bakterien und Exoenzyme". Arch. Mikrobiol. vol. 47 pp. 167-200, 1963.

[25] R. D. de la Rivie`re, "Notice Ne'crologique sur M. Maurice Lemoigne (1883-1967) C. R. Acad. des Sci., Paris, t. 12 jun, pp. 264, 1967.

[26] M. Lemoigne, "Production d'acide $\beta$-oxybutyrique par certaines bact'eries du groupe du Bacillus subtilis". C.R. Hebd. Seances Acad. Sci., vol. 176 pp. 1761, 1923.

[27] M. Lemoigne, "Etudes sur l'autolyse microbie acidification par formation d'acide $\beta$ oxybutyrique, Ann. Inst. Pasteur. vol. 39. pp.144. 1925

[28] M. Lemoigne, "Produits de l'hydration et de polymerisation de l'acide $\beta$-oxobutyrique". Bull. Soc. Chem. Biol. (Paris), vol. 8 pp. 770-782, 1926.

[29] M. Lemoigne, "Etudes sur l'autolyse microbienne. Origine de l'acide $\beta$-oxybutyrique form'e par autolyse". Ann. Inst. Pasteur (Paris), vol. 39 pp. 144, 1927.

[30] C. Weibull, "Characterization of the protoplasmic constituents of Bacillus Megaterium". J. Bacteriol. Dec; vol. 66(6), pp. 696-702, 1953

[31] D. H. Williamson and J. F. Wilkinson "The isolation and estimation of the poly-betahydroxybutyrate inclusions of Bacillus species". J. Gen. Microbiol. Aug; vol. 19(1), pp. 198209, 1958

[32] R. M. Macrae, J. F. Wilkinson. "Poly-beta-hyroxybutyrate metabolism in washed suspensions of Bacillus cereus and Bacillus megaterium". J. Gen. Microbiol. Aug; vol. 19(1), pp. 210222,1958

[33] M. Doudoroff and R. Y. Stanier, "Role of poly- $\beta$-hydroxybutyric acid in the assimilation of organic carbon by bacteria". Nature, vol. 183, pp. 1440. 1959

[34] R. Y. Stanier, M. Doudoroff, R. Kunisawa, R. Contopoulou. "The role of organic substrates in bacterial photosynthesis". Proc. Natl. Acad. Sci. U S A, Aug; vol. 45(8), pp. 1246-1260, 1959

[35] J. M. Merrick, M. Doudoroff "Enzymatic synthesis of poly-beta-hydroxybutyric acid in bacteria". Nature, Mar 18; vol. 189, pp. 890-892, 1961

[36] C. J. Lusty and M. Doudoroff, "Poly- $\beta$-hydroxybutyrate depolymerases of Pseudomonas lemoignei”. Biochemistry, vol. 56, pp. 960-965. 1966.

[37] D. G. Lundgren, R. Alper, C. Schnaitman and R.H. Marchessault, "Characterization of PolyBeta-Hydroxybutyrate Extracted from Different Bacteria”. J. Bacteriol, vol. 89, pp. 245-51, 1965.

[38] H. G. Schlegel , H. Kaltwasser, G. Gottschalk . " [A submersion method for culture of hydrogen-oxidizing bacteria: growth physiological studies.] "[Article in German]Arch. Mikrobiol., vol. 38 pp. 209-222, 1961.

[39] J. M. Merrick and M. Doudoroff, "Depolymerization of poly-beta-hydroxybutyrate by intracellular enzyme system”. J. Bacteriol., Jul; vol. 88, pp. 60-71. 1964 
[40] Griebel R, Z. Smith and M. Merrick, "Metabolism of poly-beta-hydroxybutyrate. I. Purification, composition, and properties of native poly-beta-hydroxybutyrate granules from Bacillus megaterium. Biochemistry". Oct; vol. 7(10), pp. 3676-3681, 1968.

[41] V. Oeding, and H. G. Schegel, " $\beta$-Ketothiolase from Hydrogenomonas eutropha H16 and its significance in the regulation of poly- $\beta$-hydroxybutyrate metabolism". Biochem, vol. J. 134 pp. 239-248, 1973.

[42] P. J. Senior and E. A. Dawes, The regulation of poly- $\beta$-hydroxybutyrate metabolism in Azotobacter beijerinckii. Biochem. J., vol. 134, pp. 225-238. 1973.

[43] L. L. Wallen, and W. K. Rohwedder. "Poly- $\beta$-hydroxy-alkanoate from activated sludge". Environ. Sci. Technol, vol. 8 pp. 576- 579, 1974.

[44] R. H. Findlay, and D. C. White, "Polymeric beta- hydroxyalkanoates from environmental samples and Bacillus megaterium". Appl. Environ. Microbiol., vol. 45 pp. 71-78. 1983.

[45] De Smet, M. J., Eggink, G., Withold, B. B., Kingma, J. and Wynberg, H. "Characterization of intracellular inclusions formed by Pseudomonas oleovorans during growth on octane". J. Biotechnol., vol. 154, pp. 870-878, 1983.

[46] G. W. Huisman, O. de Leeuw, G. Eggink, and B. Witholt, "Synthesis of polyhydroxyalkanoates is a common feature of fluoresent pseudomonads". Appl. Environ. Microbiol., vol. 55 pp. 1949-1954, 1989.

[47] R. Fernandez-Castillo, F. Rodrigues-Valera, J. Gonzalez-Ramos, and F. Ruiz-Berraquero, "Accumulation of poly( $\beta$-hydoxybutyrate) by halobacteria". Appl. Environ. Microbiol., vol. 51 pp. 214-216, 1986.

[48] J. Anderson and E. A. Dawes, "Occurrence, metabolism, metabolic role, and industrial uses of bacterial polyhydroxyalkanoates". Microbiol. Rev., vol. 54(4), pp. 450-472, 1990.

[49] A. Steinbüchel, "Polyhydroxyalkanoic acids. In: Byrom D (ed) "Biomaterials: novel materials from biological sources". Stockton, New York, pp. 124-213, (1991).

[50] A. Steinbüchel, B. Füchtenbusch, V. Gorenflo, S. Hein, R. Jossek, S. Langenbach, and B. H. Rehm, "Biosynthesis of polyesters in bacteria and recombinant organisms". Polym. Degrad. Stab., vol. 59 pp. 177-182, 1997.

[51] A. Steinbüchel and S. Hein, "Biochemical and molecular basis of polyhydroxyalkanoic acids in microorganism, in "Biopolyester"' A. Steinbuchel, Babel, W., (Eds), Adv. Biochem. Eng. Biotechnol., vol. 71 pp. 81-123, 2001.

[52] M. S. Shabeb, M. Younis, A. A. Amara, and A. Shoreit. "Production of PHB-co-PHV from Compost Bioremediation by Purple non-sulfur bacteria". Egyptian. J. Biotechnol., vol. 19 pp. 467-478, 2005.

[53] F. F. Hezayen, B. H. Rehm, R. Eberhardt, and A. Steinbüchel, "Polymer production by two newly isolated extremely halophilic archaea: application of a novel corrosion-resistant bioreactor". Appl. Microbiol. Biotechnol. vol. 54, pp. 319-325. 2000.

[54] F. F. Hezayen, A. Steinbüchel, and B. H. Rehm, Biochemical and enzymological properties of the polyhydroxybutyrate synthase from the extremely halophilic archaeon strain 56. Arch. Biochem. Biophys. vol. 403, pp. 284-291. 2002.

[55] Baliga, N.S., Bonneau, R., Facciotti, M.T., Pan, M., Glusman, G., Deutsch, E.W., Shannon, P., Chiu, Y., Weng, R.S., Gan, R.R., Hung, P., Date, S.V., Marcotte, E., Hood, L., and Ng, W.V. (2004). Genome sequence of Haloarcula marismortui: a halophilic archaeon from the Dead Sea. Genome Res. vol. 14, pp. 2221-2234. 
[56] A. Quaiser, T. Ochsenreiter, H.P. Klenk, , A. Kletzin, A.H. Treusch, G. Meurer, J. Eck, C.W. Sensen, and C. Schleper, "First insight into the genome of an uncultivated crenarchaeote from soil”. Environ. Microbiol. vol. 4, pp. 603-611. 2002.

[57] H. Rehm and A. Steinbuchel, "Heterologous expression of the acyl-acyl carrier protein thioesterase gene from the plant Umbellularia californica mediates polyhydroxyalkanoate biosynthesis in recombinant Escherichia coli", Appl. Microbiol. Biotechnol., vol. 55(2), pp. 205-209, 2001.

[58] R. G. Lageveen, G. W. Huisman, H. Preusting, P. Ketelaar, G. Eggink, and A. Witholt, "Formation of polyesters by Pseudomonas oleovorans: effect of substrates on formation and composition of poly $(R)$-3-hydroxyalkanoates and poly $(R)$-3-hydroxyalkenoates". Appl. Environ. Microbiol., vol. 54 pp. 2924-2932, 1988.

[59] C. Abe, Y. Taima, Y. Nakamuraand Y. Doi, "New bacterial copolyesters of 3hydroxyalkanoates and 3-hydroxy-ù-fluoroalkanoates produced by Pseudomonas oleovorans". Polym. Commun., vol. 31 pp. 404-406, 1990.

[60] Y. Doi, C. Abe, "Biosynthesis and characterization of a new bacterial copolyester of 3hydroxyalkanoates and 3-hydroxy- $\omega$-chloroalkanoates". Macromolecules, vol. 23 pp. 37053707, (1990).

[61] K. Fritzsche, R. W. Lenz, and R. C. Fuller, "Bacterial polyesters containing branched poly $(\beta$ hydroxyalkanoate) units”. Int. J. Biol. Macromol., vol. 12 pp. 92-101, 1990a.

[62] K. Fritzsche, R. W. Lenz, and R. C. Fuller, "Production of unsaturated polyesters by Pseudomonas oleovorans". Int. J. Biol. Macromol., vol. 12 pp. 85-91, 1990b.

[63] Y. B. Kim, R. W. Lenz, and R. C. Fuller, "Poly( $\beta$-hydroxyalkanoate) copolymers containing brominated repeating units produced by Pseudomonas oleovorans.". Macromolecules. vol. 25 pp. 1852-1857, 1992.

[64] M. H. Choi, and S. C. Yoon, "Polyester biosynthesis characteristics of Pseudomonas citronellolis grown on various carbon sources, including 3-methyl-branched substrates". Appl. Environ. Microbiol, vol. 60 pp. 3245-3254, 1994.

[65] J. M. Curley, B. Hazer, R. W. Lenz, and R. C. Fuller, "Production of poly(3hydroxyalkanoates) containing aromatic substituents by Pseudomonas oleovorans". Macromolecules, vol. 29 pp. 1762-1766, 1996.

[66] J. J. Song, and S. C. Yoon, "Biosynthesis of novel aromatic copolyesters from insoluble 11phenoxyundecanoic acid by Pseudomonas putida BMO1". Appl. Environ. Microbiol., vol. 62 pp. 536-544, 1996.

[67] G. J. M. De Koning, M. Kellerhals, C. van Mers, and B. Witholt, "A process for the recovery of poly(3-hydroxyalkanoate) from pseudomonads". 2. Process development and economic evaluation". Bioprocess. Eng, vol. 17 pp. 15-21, 1997.

[68] B. H. Rehm, A. Steinbüchel, "Biochemical and genetic analysis of PHA synthases and other proteins required for PHA synthesis". Int. J. Biol. Macromol., vol. 25, pp. 3-19. 1999.

[69] D. Byrom "Polymer synthesis by micro-organisms: technology and economics". Trends Biotechnol, vol. 5 pp. 246-250, 1987.

[70] P. P. King, "Biotechnology. An industrial view". J. Chem. Tech. Biotechnol., vol. 32 pp. 2-8, 1982.

[71] Y. Doi., "Microbial synthesis, physical properties, and biodegradability of polyhydroxyalkanoates". Macromol. Symp., 98 pp. 585-599, 1995. 
[72] R. A. Gross, C. DeMello, R. W. Lenz, H. Brandl, and R. C. Fuller, "Biosynthesis and characterization of poly( $\beta$-hydroxyalkanoates) produced by Pseudomonas oleovorans". Macromolecules, vol. 22 pp. 1106-1115, 1989.

[73] J. W. Moore, “Degradable plastics”. Mod. Plastics, vol. 69(13) pp. 58-63. 1992.

[74] A. A. Amara, M. Abd Ellatif, M. Younis and M. Shabeb, "Strategy for economic production of PHAs (Polyhydroxyalkanoates) by bacterial isolates as a biotechnological model in Arabic countries". Egyptian J. of Appl. Sci., vol. 20 (11B) pp, 455-473, 2005.

[75] T. Yamane, "Yield of poly-D()-3-hydroxybutyrate from various carbon sources: a theoretical study". Biotechnol. Bioeng., vol. 41 pp. 165-170, 1993

[76] B. Kothuis, F. Schelleman, "Environmental economic comparison of biotechnology with traditional alternatives". In: Meesters KHP, editor. Production of poly-(3-hydroxyalkanoates) from waste streams. Delft: Tudelft. Press; p. 4. 1998.

[77] S. Y. Lee, and J. Choi, "Polymer Degrad”. Stabil. vol. 387, pp. 59, 1998.

[78] A. A. Amara and R. S. Salem, "Characterization of PHA depolymerase in phenol degrading bacteria". International Journal of Biotechnology and Biochemistry, vol. 3 pp. 69-81, 2007.

[79] J. N. Baptist, "Process for preparing poly- $\beta$-hydroxybutyric acid". US Patent No.3,036,959. 1962.

[80] J. N. Baptist January USA. patent 3,072,538. 1963a.

[81] J. N. Baptist October USA. patent 3,107,172. 1963 b.

[82] A. Webb, February 1990. USA. patent 4,900,299.

[83] F. Martini, L. Perazzo, and P. Vietto, May USA. patent 4,826,493. 1989a.

[84] F. Martini, L. Perazzo, and P. Vietto, November USA. patent 4,880,592. 1989 b.

[85] H. Son, G. Park and S. Lee, "Growth-associated production of poly- $\beta$-hydroxybutyrate from glucose or alcoholic distillery waste water by Actinobacillus sp". EL-9. Biotechnol. Lett. vol. 18, pp. 1229-1234, 1996.

[86] T. Kauffman, F. X. Brady, P. P. Puletti, and G. Raykovitz, December USA. patent 5,169,889. 1992.

[87] R. N. Reusch, and W. H. Reusch, November USA. patent 5,266,422. 1993.

[88] R. N. Reusch, and W. H. Reusch, May USA. patent RE035257. 1996.

[89] R. H. Marchessault, P. F. LePoutre, and P. E. Wrist, September USA. patent 5,451,456. 1995.

[90] M. Yalpani, July 1993. USA. patent 5, 229, 158.

[91] R. Rutherford, W. J. Hammar, and G. N. Babu, March, USA. patent 5,614,576. 1997.

[92] H. Müller, and D. Seebach, "Poly(hydroxyalkanoates): a fifth class of physiologically important organic biopolymers?" Angew. Chem, vol. 105 pp. 483-509, 1993.

[93] K. Sudesh, C.Y. Loo, L. K. Goh, T. Iwata and M. Maeda, "The oil-absorbing property of polyhydroxyalkanoate films and its practical application: a refreshing new outlook for an old degrading material". Macromol. Biosci., Nov vol. 12;7(11), pp. 1199-1205, 2007.

[94] A. Steinbüchel, 1996. Polyhydroxyalkanoic acids. In: Biotechnology Vol. 6. Rehm, H. J., Reed, G., Püler, A., Stadler, P. (Eds), Heidelberg, Germany:Wiley-VCH, p. 403.

[95] S. F. Williams, D. P. Martin, D. M. Horowitz, and O. P. Peoples, "PHA applications: addressing the price performance issue I. Tissue engineering". Int. J. Biol. Macromol., vol. 25 pp. 111-121, 1999. 
[96] A. M. Van der Walle, G. J. H Busiman, R. A. Weusthuis, and G. Eggink, "Development of environmentally friendly coatings and paints using medium-chain-length poly(3hydroxyalkanoates) as the polymer binder". Int. J. Biol. Macromol., vol. 25 pp. 123-128, 1999.

[97] P. A. Holmes, "Applications of PHB: a microbially produced biodegradable thermoplastic". Phys. Technol., vol. 16 pp. 32-36. 1985.

[98] Y. Doi. "Microbial polyesters". VCH Publishers, Inc., Yokohama, Japan. 1990.

[99] Y. Doi, Y. Kawaguchi, N. Koyama, S. Nakamura, M. Hiramitsu, Y. Yoshida, U. Kimura "Synthesis and degradation of polyhydroxyalkanoates in Alcaligenes eutrophus". FEMS Microbiol. Rev., vol. 103 pp. 103-108, (1992).

[100] A. A. Amara, B. H. Rehm and A. Steinbuchel, "Biopolymer overproduction by new mutants using simple methods for selection". "In DAAD-Bioforum-Berlin-Grenzenlos forschen", DAAD, Biotechnologische Methoden, pp. 231-239, 2001.

[101] A. A. Amara, A. Steinbuchel and B.H. Rehm, "In vivo evolution of the Aeromonas punctata polyhydroxyalkanoate (PHA) synthase: isolation and characterization of modified PHA synthases with enhanced activity". Appl. Microbiol. Biotechnol., vol. 59(4-5), pp. 477482, 2002.

[102] S. Taguchi, A. Maehara, K. Takase, M. Nakahara, H. Nakamura and Y. Doi, "Analysis of mutational effects of a polyhydroxybutyrate (PHB) polymerase on bacterial PHB accumulation using an in vivo assay system”. FEMS Microbiol. Lett., vol. 198(1), pp. 65-71, 2001.

[103] S. Taguchi, H. Nakamura, T. Hiraishi, I. Yamato and Y. Doi, "In vitro evolution of a polyhydroxybutyrate synthase by intragenic suppression-type mutagenesis". J. Biochem., (Tokyo), vol. 131(6), pp. 801-806, 2002.

[104] C. J. Addison, S. H. Chu and R. N. Reusch, Polyhydroxybutyrate-enhanced transformation of log-phase Escherichia coli, Biotechniques vol. 37(3), pp. 376-378, 380, 382, 2004.

[105] J. C. Knowles, "Development of a natural degradable polymer for orthopaedic use". J. Med. Eng. Technol., vol. 17(4), pp. 129-137, 1993.

[106] C. Kunze, T. Freier, S. Kramer and K.P. Schmitz, "Anti-inflammatory prodrugs as plasticizers for biodegradable implant materials based on poly(3-hydroxybutyrate)". J. Mater. Sci. Mater. Med., vol. 13(11), pp. 1051-1055, 2002.

[107] S. Cheng, G.Q. Chen, M. Leski, B. Zou, Y. Wang and Q. Wu, "The effect of D,L-betahydroxybutyric acid on cell death and proliferation in L929 cells". Biomaterials, vol. 27(20), pp. 3758-3765, 2006.

[108] S. K. Misra, S. P. Valappil, I. Roy and A. R. Boccaccini, "Polyhydroxyalkanoate (PHA)/inorganic phase composites for tissue engineering applications". Biomacromolecules vol. 7(8), pp. 2249-2258, 2006.

[109] S. P. Valappil, S.K. Misra, A.R. Boccaccini and I. Roy, "Biomedical applications of polyhydroxyalkanoates: an overview of animal testing and in vivo responses". Expert. Rev. Med. Devices, vol. 3(6), pp. 853-868, 2006.

[110] G. A. van der Walle, G.J. de Koning, R.A. Weusthuis and G. Eggink, "Properties, modifications and applications of biopolyesters". Adv Biochem Eng Biotechnol vol. 71, pp. 263-91, 2001.

[111] Y. W. Wang, F. Yang, Q. Wu, Y.C. Cheng, P.H. Yu, J. Chen and G.Q. Chen, "Effect of composition of poly(3-hydroxybutyrate-co-3-hydroxyhexanoate) on growth of fibroblast and osteoblast". Biomaterials, vol. 26(7), pp. 755-61, 2005. 
[112] B. Nebe, C. Forster, H. Pommerenke, G. Fulda, D. Behrend, U. Bernewski, K. P. Schmitz, and J. Rychly, "Structural alterations of adhesion mediating components in cells cultured on poly $\beta$-hydroxy butyric acid". Biomaterials , vol. 22 pp. 2425-2434, 2001.

[113] I. Shishatskaya and T. G. Volova, "A comparative investigation of biodegradable polyhydroxyalkanoate films as matrices for in vitro cell cultures". J. Mater. Sci. Mater. Med., vol. 15(8), pp. 915-923, 2004.

[114] I. Shishatskaya, T. G. Volova, A. P. Puzyr, O. A. Mogilnaya and S. N. Efremov, "Tissue response to the implantation of biodegradable polyhydroxyalkanoate sutures". J. Mater. Sci. Mater. Med., vol. 15(6), pp. 719-728, 2004.

[115] I. Shishatskaya, T. G. Volova, S. A. Gordeev and A. P. Puzyr, "Degradation of P(3HB) and $\mathrm{P}(3 \mathrm{HB}-\mathrm{co}-3 \mathrm{HV})$ in biological media". J. Biomater. Sci. Polym. Ed, vol. 16(5), pp. 643$657,2005$.

[116] I. Shishatskaya, I. A. Khlusov and T. G. Volova, "A hybrid PHB-hydroxyapatite composite for biomedical application: production, in vitro and in vivo investigation". J. Biomater. Sci. Polym. Ed, vol. 17(5), pp. 481-498, 2006.

[117] I. Shishatskaya, O. N. Voinova, A. V. Goreva, O. A. Mogilnaya and T. G. Volova, "Biocompatibility of polyhydroxybutyrate microspheres: in vitro and in vivo evaluation", J. Mater. Sci. Mater. Med., vol. 19(6), pp. 2493-2502, 2008.

[118] A. Tezcaner, K. Bugra, and V. Hasirci, "Retinal pigment epithelium cell culture on surface modified poly(hydroxybutyrate-co-hydroxyvalerate) thin films. Biomaterials, vol. $24 \mathrm{pp}$. 4573-4583, 2003.

[119] Y. Tesema, Y., Raghavan, D. and J. Stubbs, "Bone cell viability on collagen immobilized poly (3-hydroxybutrate-co-3-hydroxyvalerate) membrane: effect of surface chemistry". J. Appl. Polym. Sci., vol. 93 pp. 2445-2453, 2004.

[120] T. Malm, S. Bowald, S. Karacagil, A. Bylock and C. Busch, "A new biodegradable patch for closure of atrial septal defect. An experimental study", Scand. J. Thorac. Cardiovasc. Surg., vol. 26(1), pp. 9-14, 1992.

[121] T. Malm, S. Bowald, A. Bylock, T. Saldeen and C. Busch, "Regeneration of pericardial tissue on absorbable polymer patches implanted into the pericardial sac. An immunohistochemical, ultrastructural and biochemical study in the sheep", Scand. J. Thorac. Cardiovasc. Surg., vol. 26(1), pp. 15-21, 1992.

[122] T. Malm, S. Bowald, A. Bylock, C. Busch and T. Saldeen, "Enlargement of the right ventricular outflow tract and the pulmonary artery with a new biodegradable patch in transannular position”, Eur. Surg. Res., vol. 26(5), pp. 298-308, 1994.

[123] Z. Cai, L. Wang, X. Hou and G. Cheng, " [Application of biodegradable polyhydroxybutyrate in medicine and tissue engineering] ", Sheng Wu Yi Xue Gong Cheng Xue Za Zhi vol. 19(2), pp. 306-309, 2002.

[124] A. C. Kassab, K. Xu, E. B. Denkbas, Y. Dou, S. Zhao and E. Piskin, Rifampicin carrying polyhydroxybutyrate microspheres as a potential chemoembolization agent, J. Biomater, Sci. Polym. Ed. vol. 8(12), pp. 947-961, 1997.

[125] S. P. Valappil, S. K. Misra, A. R. Boccaccini and I. Roy, "Biomedical applications of polyhydroxyalkanoates: an overview of animal testing and in vivo responses". Expert. Rev. Med. Devices. vol. 3(6), pp. 853-868, 2006.

[126] G. Q. Chen and Q. Wu, "The application of polyhydroxyalkanoates as tissue engineering materials", Biomaterials, vol. 26(33), pp. 6565-6578, 2005. 
[127] G. Ostle, and J. G. Holt, "Nile Blue A as a fluorescent stain for poly- $\beta$-hydroxybutyrate". Appl. Environ. Microbiol., vol. 44 pp. 238-241, 1982.

[128] H. G. Schlegel, R. Lafferty, and I. Krauss, "The isolation of mutants not accumulating poly- $\beta$-hydroxybutyric acid”. Arch. Mikrobiol., vol. 71 pp. 283-294, 1970.

[129] P. Spiekermann, B. H. Rehm, R. Kalscheuer, D. Baumeister and A. Steinbuchel, "A sensitive, viable-colony staining method using Nile red for direct screening of bacteria that accumulate polyhydroxyalkanoic acids and other lipid storage compounds". Arch. Microbiol., vol. 171(2), pp. 73-80, 1999.

[130] H. Brandl, R. A. Gross, R. W. Lenz, and R. C. Fuller, "Pseudomonas oleovorans as a source of poly $(\beta$-hydroxyalkanoates) for potential applications as biodegradable polyesters". Appl. Environ. Microbiol, vol. 54 pp. 1977-1982, 1988.

[131] A. Timm and A. Steinbuchel, "Formation of polyesters consisting of medium-chain-length 3-hydroxyalkanoic acids from gluconate by Pseudomonas aeruginosa and other fluorescent pseudomonads". Appl. Environ. Microbiol., vol. 56(11), pp. 3360-3367, 1990.

[132] Schubert, A. Steinbuchel and H.G. Schlegel, "Cloning of the Alcaligenes eutrophus genes for synthesis of poly-beta-hydroxybutyric acid (PHB) and synthesis of PHB in Escherichia coli". J. Bacteriol., vol. 170(12), pp. 5837-5847, 1988.

[133] S. C. Slater, W. H. Voige, and D. E. Dennis, "Cloning and expression in Escherichia coli of the Alcaligenes eutrophus H16 poly- $\beta$-hydroxybutyrate biosynthetic pathway". J. Bacteriol., vol. 170 pp. 4431-4436. 1988.

[134] O. P. Peoples, and A. J. Sinskey, "Poly- $\beta$-hydroxybutyrate (PHB) biosynthesis in Alcaligenes eutrophus H16. Identification and characterization of the PHB polymerase gene (phbC)". J. Biol. Chem., vol. 264 pp. 15298-15303, 1989.

[135] F. A. Jackson, and E. A., Dawes. "Regulabon of the tricarboxylic acid cycle and poly-bhydoxybutyrate metabolism in Azotobacter beijerinckii grown under nitrigen or oxygen limitation”. J. Gen. Microbiol., vol. 97 pp. 303-312, 1976

[136] Y. Asada, M. Miyake, J. Miyake, R. Kurane and Y. Tokiwa, "Photosynthetic accumulation of poly-(hydroxybutyrate) by cyanobacteria-the metabolism and potential for $\mathrm{CO}_{2}$ recycling". Int. J. Biol. Macromol. vol. 25(1-3), pp. 37-42, 1999.

[137] A. Mansfield, A. J. Anderson and L. A. Naylor, "Regulation of PHB metabolism in Alcaligenes eutrophus". Canadian Journal of Microbiology, vol. 41(Suppl. 1), pp. 44-49. 1995

[138] S. Slater, K. L. Houmiel, M. Tran, T. A. Mitsky, N. B. Taylor, S. R. Padgette, and K. J. Gruys, "Multiple $\beta$-ketothiolases mediate poly( $\beta$-hydroxyalkanoate) copolymer synthesis in Ralstonia eutropha". J. Bacteriol., vol. 180 pp. 1979-1987, 1998.

[139] G. N. M. Huijberts, G. Eggink, P. de Waard, G. W. Huisman, and B. Witholt, "Pseudomonas putida KT2442 cultivated on glucose accumulates poly(3-hydroxyalkanoates) consisting of saturated and unsaturated monomers. " Appl. Environ. Microbiol., vol. 58 pp. 536-544, 1992.

[140] H. Rehm, N. Kruger and A. Steinbuchel, "A new metabolic link between fatty acid de novo synthesis and polyhydroxyalkanoic acid synthesis". The PHAG gene from Pseudomonas putida KT2440 encodes a 3-hydroxyacyl-acyl carrier protein-coenzyme a transferase". J. Biol. Chem., vol. 273(37), pp. 24044-24051, 1998.

[141] E. Valentin and D. Dennis, "Production of poly(3-hydroxybutyrate-co-4-hydroxybutyrate) in recombinant Escherichia coli grown on glucose", J. Biotechnol., vol. 58(1), pp. 33-38, 1997. 
[142] N. Hoffmann, A. Steinbüchel, and B. H. Rehm, "The Pseudomonas aeruginosa phaG gene product is involved in the synthesis of polyhydroxyalkanoic acid consisting of mediumchain-length constituents from non-related carbon sources ". FEMS Microbiol. Lett. vol. 184, pp. 253-259, 2000

[143] N. Hoffmann, A. Steinbuchel and B. H. Rehm, "Homologous functional expression of cryptic phaG from Pseudomonas oleovorans establishes the transacylase-mediated polyhydroxyalkanoate biosynthetic pathway". Appl. Microbiol. Biotechnol., vol. 54(5), 665$670,2000$.

[144] N. Hoffmann, A. A. Amara, B. B. Beermann, Q. Qi, H. J. Hinz and B. H. Rehm "Biochemical characterization of the Pseudomonas putida 3-hydroxyacyl ACP:CoA transacylase which diverts intermediates of fatty acid de novo biosynthesis". J. Biol. Chem., vol. 277 pp. 42926-42936, 2002.

[145] C. DiRusso, "Primary sequence of the Escherichia coli fadBA operon, encoding the fatty acid-oxidizing multienzyme complex, indicates a high degree of homology to eukaryotic enzymes". J. Bacteriol, vol. 172 pp. 6459-6468, 1990.

[146] S. Langenbach, B. H. Rehm and A. Steinbuchel, "Functional expression of the PHA synthase gene phaC1 from Pseudomonas aeruginosa in Escherichia coli results in poly(3hydroxyalkanoate) synthesis", FEMS Microbiol. Lett., vol. 150(2), pp. 303-309, 1997.

[147] Q. Qi, B. H. Rehm and A. Steinbuchel, "Synthesis of poly(3-hydroxyalkanoates) in Escherichia coli expressing the PHA synthase gene phaC2 from Pseudomonas aeruginosa: comparison of PhaCl and PhaC2". FEMS Microbiol. Lett., vol. 157(1), pp. 155-162, 1997.

[148] S. Fiedler, A. Steinbuchel and B. H. Rehm, "The role of the fatty acid beta-oxidation multienzyme complex from Pseudomonas oleovorans in polyhydroxyalkanoate biosynthesis: molecular characterization of the fadBA operon from P. oleovorans and of the enoyl-CoA hydratase genes phaJ from $P$. oleovorans and Pseudomonas putida". Arch. Microbiol., vol. 178(2), pp. 149-160, 2002.

[149] T. Fukui, and Y. Doi., "Cloning and analysis of the poly(3-hydroxybutyrate-co-3hydroxyhexanoate) biosynthesis genes of Aeromonas caviae". J. Bacteriol., vol. $179 \mathrm{pp}$. 4821- 4830,1997.

[150] T. Tsuge, T. Fukui, H. Matsusaki, S. Taguchi, G. Kobayashi, A. Ishizaki and Y. Doi, “ Molecular cloning of two $(R)$-specific enoyl-CoA hydratase genes from Pseudomonas aeruginosa and their use for polyhydroxyalkanoate synthesis". FEMS Microbiol. Lett., vol. 184(2), pp. 193-198, 2000.

[151] K. Taguchi, Y. Aoyagi, H. Matsusaki, T. Fukui and Y. Doi, "Co-expression of 3-ketoacylACP reductase and polyhydroxyalkanoate synthase genes induces PHA production in Escherichia coli HB101 strain”. FEMS Microbiol. Lett., vol. 176(1), pp. 183-190, 1999.

[152] Q. Ren, N. Sierro, B. Witholt, and B. Kessler, "FabG, an NADPH-dependent 3-ketoacyl reductase of Pseudomonas aeruginosa, provides precursors for medium-chain-length poly-3hydroxyalkanoate biosynthesis in Escherichia coli". J. Bacteriol., vol. 182 pp. 2978-2981, 2000 .

[153] J. E. Thijsse, "Fatty-acid accumulation by acrylate inhibition of $\beta$-oxidation in an alkaneoxidizing Pseudomonas". Biochim. Biophys. Acta, vol. 84 pp. 195-197, 1964.

[154] S. Miyakawa, K. Suzuki, T. Noto, Y. Harada, and H. Okazaki, "Thiolactomycin, a new antibiotic. IV. Biological properties and chemotherapeutic activity in mice". J. Antibiot., vol. 35 pp. 411-419, 1982. 
[155] G. M. Jr. Helmkamp, D. J. Brock, and K. Bloch, "Beta-hydroxydecanoyl thioester dehydrase. Specificity of substrates and acetylenic inhibitors". J. Biol. Chem., vol. 243 pp. 3229-3231, 1968.

[156] R. J. Heath, Y. T. Yu, M. A. Shapiro, E. Olson, and C. Rock, "Broad spectrum antimicrobial biocides target FabI component of fatty acid synthesis". J. Biol. Chem., vol. 273 pp. 30316-30320, 1998.

[157] F. Turnowsky, K. Fuchs, C. Jeschek, and G. Hogenauer, "envM genes of Salmonella typhimurium and Escherichia coli”. J. Bacteriol., vol. 171 pp. 6555-6565. 1989.

[158] G. D'Agnolo, I. S. Rosenfeld, J. Awaya, S. Omura, and P. R. Vagelos, "Inhibition of fatty acid synthesis by the antibiotic cerulenin. Specific inactivation of beta-ketoacyl-acyl carrier protein synthetase”. Biochim. Biophys. Acta, vol. 326 pp. 155-156, 1973.

[159] Q. Qi, A. Steinbuchel and B. H. Rehm, "Metabolic routing towards polyhydroxyalkanoic acid synthesis in recombinant Escherichia coli (fadR): inhibition of fatty acid beta-oxidation by acrylic acid”. FEMS Microbiol. Lett., vol. 167(1), pp. 89-94, 1998.

[160] H. M. Alvarez, , R. Kalscheuer, and A. Steinbüchel, "Accumulation of storage lipids in species of Rhodococcus and Nocardia and effect of inhibitors and polyethylene glycol". Fett/Lipid, vol. 99, pp. 239-246, 1997.

[161] R. V. Antonio, A. Steinbüchel and B. H. Rehm, "Analysis of in vivo substrate specificity of the PHA synthase from Ralstonia eutropha: formation of novel copolyesters in recombinant Escherichia coli". FEMS Microbiol. Lett. vol. 182, pp. 111-117. 2000.

[162] T. U. Gerngross and D. P. Martin, "Enzyme-catalyzed synthesis of poly[(R)-(-)-3hydroxybutyrate]: formation of macroscopic granules in vitro". Proc. Natl. Acad. Sci. U S A, vol. 92(14), pp. 6279-6783, 1995.

[163] R. Jossek and A. Steinbuchel, "In vitro synthesis of poly(3-hydroxybutyric acid) by using an enzymatic coenzyme A recycling system", FEMS Microbiol. Lett., vol. 168(2), pp. 319324, 1998.

[164] R. W. Lenz, C. Farcet, P. J. Dijkstra, S. Goodwin, S. Zhang, "Extracellular polymerization of 3-hydroxyalkanoate mononers with the polymerase of Alcaligenes eutrophus". Int. J. Biol. Macromol., vol. 25 pp. 55-60, 1999.

[165] R. Jossek, R. Reichelt and A. Steinbuchel, "In vitro biosynthesis of poly(3-hydroxybutyric acid) by using purified poly(hydroxyalkanoic acid) synthase of Chromatium vinosum", Appl. Microbiol. Biotechnol., vol. 49(3), pp. 258-266, 1998.

[166] L. Su, R. W. Lenz, Y. Takagi, S. Zhang, S. Goodwin, L. Zhong, D. P . Martin, "Enzymatic polymerization of (R)-3-hydroxyalkanoates by a bacterial polymerase, Macromolecules, vol. 33, pp. 229-231, 2000.

[167] S. J. Liu and A. Steinbuchel, "Exploitation of butyrate kinase and phosphotransbutyrylase from Clostridium acetobutylicum for the in vitro biosynthesis of poly(hydroxyalkanoic acid) ”, Appl. Microbiol. Biotechnol., vol. 53(5), pp. 545-552, 2000.

[168] Q. Qi, A. Steinbuchel and B. H. Rehm, "In vitro synthesis of poly(3-hydroxydecanoate): purification and enzymatic characterization of type II polyhydroxyalkanoate synthases $\mathrm{PhaC} 1$ and PhaC2 from Pseudomonas aeruginosa". Appl. Microbiol. Biotechnol., vol. 54(1), pp. 37-43, 2000.

[169] R. N. Reush, "Poly- $\beta$-hydroxybuyrate/calcium Polyhydroxyphosphate, a biodegradable thermoplastic produced in transgenic plants". Science, vol. 256, pp. 520-523, 1989. 
[170] T. A. Leaf, M. S. Peterson, S. K. Stoup, D. Somers and F. Srienc, "Saccharomyces cerevisiae expressing bacterial polyhydroxybutyrate synthase produces poly-3hydroxybutyrate". Microbiology, vol. 142 ( Pt 5), pp. 1169-1180, 1996.

[171] J. Hahn, A. C. Eschenlauer, M. H. Narrol, D. A. Somers, and F. Srienc, "Growth kinetics, nutrient uptake, and expression of the Alcaligenes eutrophus poly( $\beta$-hydroxybutyrate) synthesis pathway in transgenic maize cell suspension cultures". Biotechnol. Prog., vol. 13 pp. 347-354, 1997.

[172] J. A. Kornblatt, and H. Rundney, "Two forms of acetoacetyl coenzyme A thiolase in yeast II. Intracellular location and relationship to growth”. J. Biol. Chem., vol. 246 pp. 4424-4430, 1971.

[173] J. C. Igual, C. Gonzalez-Bosch, and J. E. Perez-Ortin, "The POTL* gene for yeast peroxisomal thiolase is subject to there different mechanisms of regulation". Mol. Microbiol., vol. 6 pp. 1867-1875, 1992.

[174] S. Safak, N. Mercan, B. Aslim, and Y. Beyatli, "A study on the production of Poly-BetaHydroxybutyrate by some eukyryotic microorganisms". Turkish Electronic Journal of Biotechnology, pp. 11-17, 2002.

[175] B. Zhang, R. Carlson and F. Srienc, "Engineering the monomer composition of polyhydroxyalkanoates synthesized in Saccharomyces cerevisiae". Appl. Environ. Microbiol., 72(1), 536-543, 2006.

[176] R. N. Reush, "Poly- $\beta$-hydroxybuyrate/calcium Polyhydroxyphosphate, a biodegradable thermoplastic produced in transgenic plants". Science. vol. 256, pp. 520-523. 1989.

[177] E. Valentin, D. L. Broyles, L. A. Casagrande, S. M. Colburn, W. L. Creely, P. A. DeLaquil, H. M. Felton, K. A. Gonzalez, K .L. Houmiel, K. Lutke, D. A. Mahadeo, T. A. Mitsky, S. R. Padgette, S. E. Reiser, S. Slater, D. M. Stark, R. T. Stock, D. A. Stone, N. B. Taylor, G. M. Thorne, M. Tran and K. J. Gruys, "PHA production, from bacteria to plants". Int. J. Biol. Macromol., vol. 25(1-3), pp. 303-306, 1999.

[178] M. E. John and G. Keller, "Metabolic pathway engineering in cotton: biosynthesis of polyhydroxybutyrate in fiber cell. Proc. Natl. Acad. Sci. U S A, vol. 93(23), pp. 1276812773, 1996.

[179] H. Nakashita, Y. Arai, K. Yoshioka, T. Fukui, Y. Doi, R. Usami, K. Horikoshi, and I. Yamaguchi, "Production of biodegradable polyester by a transgenic tobacco". Biosci. Biotechnol. Biochem, vol. 63 pp. 870-874, 1999.

[180] S. Slater, T. A. Mitsky, K. L. Houmiel, M. Hao, S. E. Reiser, N. B. Taylor, M. Tran, H. E. Valentin, D. J. Rodriguez, D. A. Stone, S. R. Padgette, G. Kishore, and K. J. Gruys, "Metabolic engineering of Arabidopsis and Brassica for poly(3-hydroxybutyrate-co-3hydroxyvalerate) copolymer production”. Nat. Biotechnol., vol. 17 pp. 1011-1016, 1999.

[181] V. Mittendorf, E. J. Robertson, R. M. Leech, N. Kruger, A. Steinbuchel and Y. Poirier, "Synthesis of medium-chain-length polyhydroxyalkanoates in Arabidopsis thaliana using intermediates of peroxisomal fatty acid beta-oxidation", Proc. Natl. Acad. Sci. U S A, vol. 95(23), pp. 13397-13402, 1998.

[182] H. Rehm and A. Steinbuchel, "PHA synthases-the key enzymes of PHA synthesis. In 'Biopolymers". A. Steinbuchel and Y. Doi (Eds.), Wiley-VCH, Heidelberg, Germany, pp. 173-215, 2001.

[183] M. Liebergesell and A. Steinbuchel, "Cloning and nucleotide sequences of genes relevant for biosynthesis of poly(3-hydroxybutyric acid) in Chromatium vinosum strain D", Eur. J. Biochem., vol. 209(1), pp. 135-150, 1992. 
[184] M. Liebergesell, S. Rahalkar and A. Steinbuchel, "Analysis of the Thiocapsa pfennigii polyhydroxyalkanoate synthase: subcloning, molecular characterization and generation of hybrid synthases with the corresponding Chromatium vinosum enzyme", Appl. Microbiol. Biotechnol., vol. 54(2), pp. 186-194, 2000.

[185] T. U. Gerngross, K. D. Snell, O. P. Peoples, A. J. Sinskey, E. Csuhai, S. Masamune and J. Stubbe, "Overexpression and purification of the soluble polyhydroxyalkanoate synthase from Alcaligenes eutrophus: evidence for a required posttranslational modification for catalytic activity”. Biochemistry, vol. 33(31), pp. 9311-9320, 1994.

[186] M. Liebergesell, K. Sonomoto, M. Madkour, F. Mayer and A. Steinbuchel, "Purification and characterization of the poly(hydroxyalkanoic acid) synthase from Chromatium vinosum and localization of the enzyme at the surface of poly(hydroxyalkanoic acid) granules", Eur. J. Biochem., vol. 226(1), pp. 71-80, 1994.

[187] A. Timm and A. Steinbuchel, "Cloning and molecular analysis of the poly(3hydroxyalkanoic acid) gene locus of Pseudomonas aeruginosa PAO1". Eur. J. Biochem., vol. 209(1), pp. 15-30, 1992.

[188] S. Fiedler, A. Steinbuchel and B. H. Rehm, "PhaG-mediated synthesis of Poly(3hydroxyalkanoates) consisting of medium-chain-length constituents from nonrelated carbon sources in recombinant Pseudomonas fragi". Appl. Environ. Microbiol., vol. 66(5), pp. 2117-2124, 2000.

[189] Q. Qi, A. Steinbuchel and B. H. Rehm, "In vitro synthesis of poly(3-hydroxydecanoate): purification and enzymatic characterization of type II polyhydroxyalkanoate synthases PhaC1 and PhaC2 from Pseudomonas aeruginosa". Appl. Microbiol. Biotechnol., vol. 54(1), pp. 37-43, 2000.

[190] H. Rehm, Q. Qi, B .B. Beermann, H. J. Hinz and A. Steinbuchel, "Matrix-assisted in vitro refolding of Pseudomonas aeruginosa class II polyhydroxyalkanoate synthase from inclusion bodies produced in recombinant Escherichia coli". J. Biochem., vol. 358(Pt 1), pp. 263-268, 2001.

[191] Y. Jia, T. J. Kappock, T. Frick, A. J. Sinskey and J. Stubbe, "Lipases provide a new mechanistic model for polyhydroxybutyrate (PHB) synthases: characterization of the functional residues in Chromatium vinosum PHB synthase”. Biochemistry. vol. 39(14), pp. 3927-3936, 2000.

[192] K. Karplus, C. Barrett, and R. Hughey, "Hidden Markov models for detecting remote protein homologies". Bioinformatics, vol. 14 pp. 846-856, 1998.

[193] H. Rehm, R. V. Antonio, P. Spiekermann, A. A. Amara and A. Steinbuchel, "Molecular characterization of the poly(3-hydroxybutyrate) (PHB) synthase from Ralstonia eutropha: in vitro evolution, site-specific mutagenesis and development of a PHB synthase protein model". Biochim. Biophys. Acta., vol. 1594(1), pp. 178-190, 2002.

[194] U. Müh, K. Snell, E. Troyano, J. Wodzinska, A. J. Sinskey, and J. Stubbe, "In: "Biochemical principles and mechanism of biosynthesis and biodegradation of polymers", an international symposium, Abstract book, Lecture 6, Münster, Germany. 1998.

[195] A. Hoppensack, B. H. Rehm and A. Steinbuchel, "Analysis of 4-phosphopantetheinylation of polyhydroxybutyrate synthase from Ralstonia eutropha: generation of beta-alanine auxotrophic Tn5 mutants and cloning of the panD gene region". J. Bacteriol., vol. 181(5), pp. 1429-1435, 1999.

[196] J. McCool, and M. C. Cannon, "PhaC and PhaR are required for polyhydroxyalkanoic acid synthase activity in Bacillus megaterium". J. Bacteriol., vol. 183 pp. 4235-4243, 2001. 
[197] A. A. Amara and B. H. Rehm, "Replacement of the catalytic nucleophile cysteine-296 by serine in class II polyhydroxyalkanoate synthase from Pseudomonas aeruginosa-mediated synthesis of a new polyester: identification of catalytic residues". Biochem. J., vol. 374( $\mathrm{Pt} 2)$, pp. 413-421, 2003.

[198] D. S. Sheu and C.Y. Lee, "Altering the substrate specificity of polyhydroxyalkanoate synthase 1 derived from Pseudomonas putida GPo1 by localized semirandom mutagenesis". J. Bacteriol. vol. 186, pp. 4177- 4184, 2004.

[199] T. Tsuge, Y. Saito, M. Narike, K. Muneta, Y. M. Normi, Y. Kikkawa,, T. Hiraishi, , and Y. Doi, "Mutation effects of a conserved alanine (Ala510) in type I polyhydroxyalkanoate synthase from Ralstonia eutropha on polyester biosynthesis ". Macromol. Biosci. vol. 4, pp. 963-970, 2004.

[200] B. Rost and C. Sander, "Combining evolutionary information and neural networks to predict protein secondary structure". Proteins, vol. 19 pp. 55-72, 1994.

[201] U. Müh, A. J. Sinskey, D. P. Kirby, W. S. Lane, and J. Stubbe, "PHA synthase from Chromatium vinosum: cysteine 149 is involved in covalent catalysis. Biochemistry, vol. 38 pp. 826-837, 1999.

[202] J. Wodzinska, K. D. Snell, A. Rhomberg, A. J. Sinskey, K. Biemann, and J. Stubbe, "Polyhydroxybutyrate synthase: evidence for covalent catalysis". J. Am. Chem. Soc., vol. 118 pp. 6319-6320, 1996.

[203] F. Mayer, M. H. Madkour, U. Pieper-Fürst, R. Wieczorek, M. Liebergesell. and A. Steinbuchel, "Electron microscopic observations on the macromolecular organization of the boundary layer of bacterial PHA inclusion bodies". J. Gen. Appl. Microbiol., vol. 42 pp. 445-455, 1996.

[204] T. Saito, K. Suzuki, J. Yamamoto, T. Fukui, K. Miwa, K. Tomita, S. Nakauishi, S. Odani, J. I. Suzuki, and K. Ishikawa, "Cloning, nucleotide sequence, and expression in Escherichia coli of the gene for poly(3-hydroxybutyrate) depolymerase from Alcaligenes faecalis". J. Bacteriol, vol. 171 pp. 184-189, 1989.

[205] B. Klingbei, R. M. Kroppenstedt, and D. Jendrossek, "Taxonomic identification of Streptomyces exfoliates $\mathrm{K} 10$ and characterization of its poly(3-hydroxybutyrate) depolymerase gene". FEMS Microbiol. Lett., vol. 142(2-3) pp. 215-221, 1996.

[206] Schirmer, C. Matz, and D. Jendrossek, "Substrate specificities of PHA-degrading bactria and active site studies on the extracellular poly(3-hydroxyactonoic acid) $\mathrm{P}(3 \mathrm{HO})$ ] depolymerise of Pseudomonas fluorescens GK13 biovarV". Appl. Environ. Microbiol., vol. 59 pp. 1220-1227, 1995.

[207] H. Saegusa, M. Shiraki, C. Kanai, and T. Saito. "Cloning of an intracellular Poly[D(-)-3Hydroxybutyrate] depolymerase gene from Ralstonia eutropha H16 and characterization of the gene product". J. Bacteriol., vol. 183 pp. 94-100, 2001.

[208] H. Saegusa, M. Shiraki, and T. Saito, "Cloning of an intracellular D(-)-3-hydroxybutyrateoligomer hydrolase gene from Ralstonia eutropha H16 and identification of the active site serine residue by site-directed mutagenesis". J. Biosci. Bioeng., vol. 94 pp. 106-112, 2002.

[209] T. Kobayashi, M. Shiraki, T. Abe, A. Sugiyama, and T. Saito, "Purification and properties of an intracellular 3-hydroxybutyrate-oligomer hydrolase (PhaZ2) in Ralstonia eutropha H16 and its identification as a novel intracellular poly(3-hydroxybutyrate) depolymerase". J. Bacteriol., vol. 185 pp. 3485-3490, 2003. 
[210] G. M. York, J. Stubbe, and A.J. Sinskey, "The Ralstonia eutropha PhaR protein couples synthesis of the PhaP phasin to the presence of polyhydroxybutyrate in cells and promotes polyhydroxybutyrate production ”. J. Bacteriol. vol.184, pp. 59-66. 2002.

[211] T. M. Scherer, R. C. Fuller, S. Goodwin, and R. W. Lenz, "Enzymatic hydrolysis of oligomeric models of poly-3-hydroxybutyrate". Biomacromolecules, vol. 1 pp. 577-583, 2000.

[212] P. Gruchulski, F. Bouthillier, R. J. Kazlauskas, A. N. Serreqi, J. D. Schrag, E. Ziomek, and M. Cygler, "Analogs of reaction intermediates identify a unique substrate binding site in Candida rugosa lipase"." Biochemistery, vol. 33 pp. 3494-3500, 1994.

[213] K. E. Jaeger, A. Steinbuchel and D. Jendrossek, "Substrate specificities of bacterial polyhydroxyalkanoate depolymerases and lipases: bacterial lipases hydrolyze poly(omegahydroxyalkanoates) ”. Appl. Environ. Microbiol., vol. 61(8), pp. 3113-3118, 1995.

[214] M. Nojiri, and T. Saito. "Structure and function of poly(3-hydroxybutyrate) depolymerase from Alcaligenes faecalis T1". J Bacteriol 179 pp. 6965-6970, 1997.

[215] D. Jendrossek, A. Schirmer, and H. G. Schlegel, "Biodegradation of polyhydroxyalkanoic acids". Appl. Microbiol. Biotechnol., vol. 46 pp. 451-463, 1996

[216] J. Mergaert, A. Webb, C. Anderson, A. Wouters, J. Swings, "Microbial degradation of poly (3-hydroxybutyrate) and poly(3- hydroxybutyrate-co-3-hydroxyvalerate) in soil". Appl. Environ. Microbiol., vol. 59 pp. 3233-3238, 1993.

[217] J. Mergaert, C. Anderson, A. Wouters, and J. Swings, "Microbial degradation of poly(3hydroxybutyrate) and poly(3-hydroxybutyrate-co-3-hydroxyvalerate) in compost". J. Environ. Polym. Degrad., vol. 2 pp. 177-183, 1994.

[218] J. Mergaert, A. Wouters, C. Anderson, and J. Swings, "In situ biodegradation of poly(3hydroxybutyrate) and poly(3-hydroxybutyrate-co-3-hydroxyvalerate) in natural waters". Can. J. Microbiol. , vol. 41 pp. 154-159, 1995.

[219] S. F. Williams, and O. P. Peoples, "Biodegradable plastics from plants". Chemtech., vol. 26 pp. 38-44. 1996.

[220] L. Jurasek, and R.H. Marchessault, "The role of phasins in the morphogenesis of poly(3hydroxybutyrate) granules". Biomacromolecules vol. 3, pp. 256-261, 2002.

[221] A. Steinbüchel, K. Aerts, W. Babel, C. Föllner, M. Liebergesell, M. H. Madkour,., F. Mayer, I. Pieper-Fürst, A. Pries, H. E. Valentin, and R. Wieczorek, "Considerations on the structure and biochemistry of bacterial polyhydroxyalkanoic acid inclusions". Can. J. Microbiol., vol. 41 pp. 94-105, 1995.

[222] W. F. Dunlop and A. W. Robards "Ultrastructural study of poly- $\beta$-hydroxybutyrate granules from Bacillus cereus". J. Bacteriol. vol. 114 pp. 1271-1280, 1973.

[223] D. Byrom "Polyhydroxyalkanoates", In: Mobley DP (ed), "Plastic from microbes: microbial synthesis of polymers and polymer precursors". Hanser Munich, pp. 5-33, 1994.

[224] B.H. R ehm, "Polyester synthases: natural catalysts for plastics". Biochem. J., vol. 376, pp. 15-33, 2003.

[225] G. N. Barnard, and J. K. Sanders, "The poly-beta-hydroxybutyrate granule in vivo. A new insight based on NMR spectroscopy of whole cells ". J. Biol. Chem. vol. 264, pp. 3286-3291, 1989.

[226] M. Potter, H. Muller, F. Reinecke, R. Wieczorek, F. Fricke, B. Bowien, B. Friedrich and A. Steinbuchel, "The complex structure of polyhydroxybutyrate (PHB) granules: four 
orthologous and paralogous phasins occur in Ralstonia eutropha". Microbiology, vol. 150(Pt 7), pp. 2301-2311, 2004.

[227] H. Rehm, Q. Qi, B. B. Beermann, H. J. Hinz and A. Steinbuchel, "Matrix-assisted in vitro refolding of Pseudomonas aeruginosa class II polyhydroxyalkanoate synthase from inclusion bodies produced in recombinant Escherichia coli". Biochem. J., vol. 358(Pt 1), pp. 263-268, 2001.

[228] B. H. Rehm, "Biogenesis of microbial polyhydroxyalkanoate granules: a platform technology for the production of tailor-made bioparticles". Curr Issues Mol Biol. Jan; vol. 9(1), pp. 41-62, 2007 